\title{
Structural Investigations on Cryogenically Operated and Transpiration Cooled Fiber Reinforced Rocket Thrust Chambers
}

\author{
M. Ortelt ${ }^{*}$, H. Elsaesser ${ }^{*}$, A. Herbertz ${ }^{*}$, I. Mueller ${ }^{*},{ }^{\dagger}$ H. Hald \\ German Aerospace Center (DLR), Stuttgart 70569, Germany
}

\begin{abstract}
This paper will give a subsumption of the structural implementation of an integrated fiber reinforced rocket thrust chamber design, which took in the meanwhile more than one decade of development effort. Of particular interest in this case is a hybrid design approach showing Ceramic Matrix Composits as high temperature inner liner materials and a covering light weight Carbon Fiber Plastic Housing, whereas these principally different material components are joined by metallic flanges at the front edges in an extensively decoupled design philosophy, excluding compulsive loads as far as possible. In 2010 the long and intensive experimental work led into a test campaign at the European Research and Technology Test Facility P8 at DLR-Lampoldshausen using for the first time the fully integrated chamber design under cryogenic high performance conditions, using LOX/LH2. In this campaign the structural concept could be proved completely under all structurally relevant parameters. With respect to the demonstration of the system efficiency under optimized operational flow parameters a further test campaign early in 2012 had been performed at the recently renewed local P6.1-test bench. The paper discusses predominantly structural design aspects.
\end{abstract}

$d$

$=$ Coefficient of thermal expansion, $1 / \mathrm{K}$

CFRP $=$ Carbon fiber reinforced plastics

$C / C=$ Carbon fiber $/$ carbon matrix material

$E \quad=$ Young's modulus, $\mathrm{MPa}$

$G \quad=$ Shear modulus, $\mathrm{MPa}$

$\mathrm{LH} 2=$ Liquid hydrogen

LN2 = Liquid nitrogen

$L O X=$ Liquid oxygen

$v \quad=$ Poisson ratio

$p \quad=$ Pressure, bar

$\rho \quad=$ Density, $\mathrm{g} / \mathrm{cm}^{3}$

$R m, R p \quad=\quad$ Ultimate strength, elastic strength limit, $\mathrm{MPa}$

$s \quad=$ Thickness, $\mathrm{mm}$

$\sigma \quad=$ Material stress, MPa

$t \quad=$ Time, $\mathrm{s}$

$T \quad=$ Temperature, $\mathrm{K}$

$\tau=$ Coolant mass flow ratio, related to overall mass flow

\footnotetext{
* Scientist, Space System Integration, Pfaffenwaldring 38 - 40, AIAA Member - Regular New.

${ }^{\dagger}$ Head of department, System Integration, Pfaffenwaldring 38 - 40, AIAA Member 1

American Institute of Aeronautics and Astronautics
} 


\section{Introduction}

$\mathrm{T}$ He intermediately well-known development program of transpiration cooled and cryogenically operated CMC rocket thrust chambers at DLR is structurally affected in general by the combination of CMC materials at the inner chamber liner and an outer load carrying shell made of carbon fiber reinforced plastics (CFRP). Essential questions due to design requirements could be answered with respect to the introduction of an integrated composite chamber into first hot gas tests under LOX/LH2 operation. With regard to a suitable CFRP housing component in conjunction with the latest inner CMC liner material status the major design parameters could be evaluated so far, that subsequently first hot gas tests could be arranged in the middle of 2010, preliminarily applying 55 bar inner chamber pressure to a test hardware with $50 \mathrm{~mm}$ diameter. On the empirical platform multiple qualification measures have been performed before running hot gas tests, e.g. resistance tests against inner pressure up to 120 bars, tensile tests against outer loads (under ambient and cryogenic conditions), as well as Helium leakage tests. Several cold flow and hot gas tests had been conducted at the European Research and Technology Test Facility P8 at DLR Lampoldshausen, where the structural concept could be demonstrated without any damage in tests ranging up to $120 \mathrm{~s}$ of duration. In this campaign using firstly a test specimen, which was dominated by fiber reinforced structure components, the coolant mass flow ratio still ranged at high levels of about $15 \%$ related to the overall chamber mass flow.

Several aspects will be discussed in the following in detail: On the one hand one see the requirement of load carrying capacity as well as structural integrity under alternating thermo mechanical conditions (cryogenic ambient) and on the other hand there is the question of suitable mechanical interfaces connecting the injector and the nozzle extension. Further on an assortment of reliable approaches in view of hydrogen diffusion barriers is of high importance. Particularly this aspect must be considered in parallel in view of a fatigue relevant load spectrum.

High strength and light weight CFRP materials show relatively low coefficients of thermal expansion as an additional and important advantage compared to metals. As a consequence structures using CFRP are less sensitive against fatigue, especially playing out the load-de-coupling design philosophy.

DLR's current rocket thrust chamber development was embedded in the former KSK (Keramische Schubkammer)project, which was part of the German national research network Propulsion 2010 in a close co-operation with the national space propulsion industry EADS Astrium Space Transportation.

The following development phase will be placed straight DLR-internally and it will mainly be focused on inner $\mathrm{CMC}$ liner material optimizations aimed to reduce the coolant mass flow ratio retaining a damage free operation.

\section{Structural Operation Principe of the Thrust Chamber}

DLR's structural CMC chamber concept shows predominantly specifically de-coupled single parts (figure 1):

1) The inner CMC liner,

2) the outer load carrying housing made of CFRP, which shows a pure hollow-cylindrical shape,

3) metallic flanges at the front edges adjacent to CFRP and CMC bodies.

The structural operation principle can be described by the following aspects: Firstly the inner liner is assembled by ring segments (figure 1) which are extracted from flat CMC plates before (figure 3). The advantage of this practice is given on the one hand by the high grade of material homogeneity as well as highly reproducible material quality, and on the other hand by the simple material production process causing lower manufacturing costs. Subsequently the sorted and aligned segments are stacked together, whereas they are centered one to each other. The complete inner liner assembly will be inserted in the outer CFRP shell without being bonded. To fix the stack securely, the whole inner liner stacking, which shows the famous characteristic of a mechanical spring in axial direction, will be compressed from the front edges when being mounted at the metallic flanges via CFRP-Metal linkage. For this reason additionally a suitable bolt interface had been developed and qualified for the tests.

The structural operation is described in the rigging diagram, given in figure 2. It is oriented at the order of operation: When the CMC-liner is inserted in the CFRP-tube, the bolts at the front edges will be tightened, first at one edge and then at the other. When closing the last bolt row, the inner liner will be compressed gradually by the front edge flanges. 


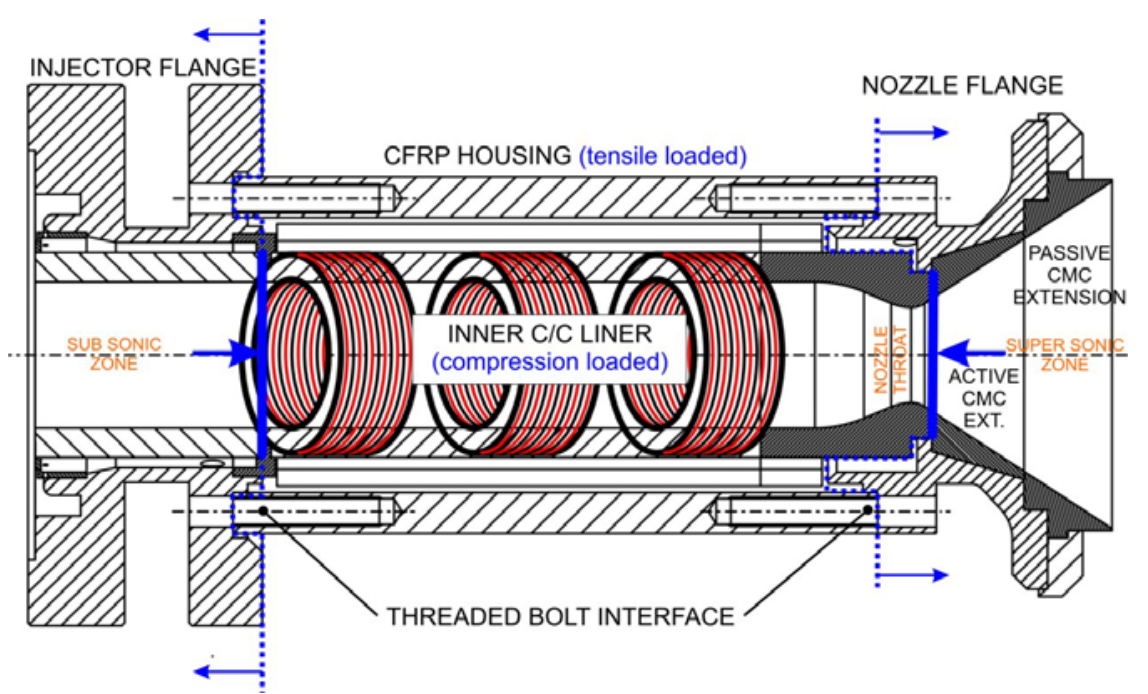

Figure 1. CMC thrust chamber assembly. All single parts of the thrust chamber body are assembled without bonding.

This compression shows a very weak curve, which represents at the beginning an extraordinary non-linear characteristic. This behavior, expressed more precisely as 'working like a good-natured spring', is very practical, because the first mounting compression process gives the construction engineer the opportunity, to define the appropriate pre-load without too high risk of overloading. Also sufficient load reserve is guaranteed against undercut of load. The mounting compression ends at a point, when the non-linear characteristic fades to a quasi-linear section. From this point on the material still shows a weak compression behavior. The corresponding young's modulus ranges at about $\mathrm{E}=6 \cdot 10^{3} \mathrm{MPa}$. Naturally the compression of the inner liner enforces simultaneously the elongation of the outer CFRP-tube, which shows much higher stiffness of about $\mathrm{E}=80 \cdot 10^{3} \mathrm{MPa}$.

The following load phase is the phase of pre-cooling. The thermal shrinkage of the CFRP $\left(\alpha_{\text {CFRP }}=6 \cdot 10^{-6} / \mathrm{K}\right)$ enforces on the one hand a further compression of the CMC up to the maximum compression point and on the other hand a further mechanical strain of itself.

After the pre-cooling phase the hot-gas operational phase starts. The up-coming inner chamber pressure enforces again a further elongation of the CFRP-housing and in parallel a slight decrease of the CMC-compression. This state is called 'Operational Point CMC' in figure 2.

The maximum CMC-compression, applied finally in the thrust chamber design is about half of the ultimate strain. This gives a high rate of structural integrity and safety. The ultimate load of the CFRP in longitudinal direction is far away from the operational load, because the surrounding housing is dimensioned against inner pressure loads, which enforces double load in circumferential direction compared to the longitudinal one.

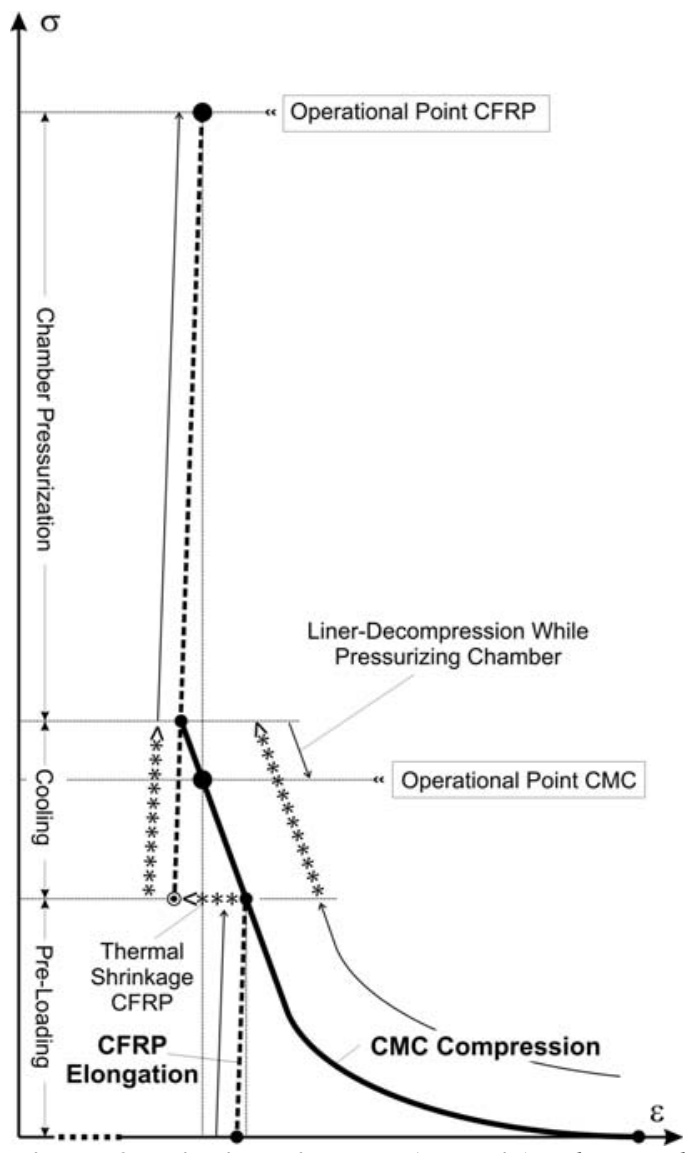

Figure 2. Rigging diagram (generic). The graph shows the structural operation, given by representative loads, displayed in the three phases mounting, pre-cooling and hot-gas-run. 


\section{Inner CMC Liner}

The inner liner can be easily composed by a variety of separate CMC rings, whereas those rings can show completely different material properties like chemical or physical characteristics. Due to the specific DLR thrust chamber design the mechanical loads are of lower interest but in this context the thermochemical resistance and the

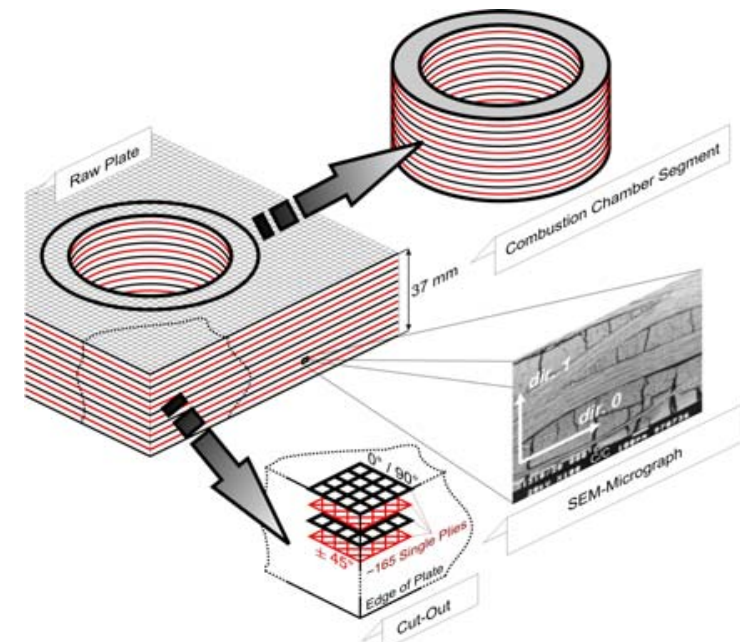

Figure 3. Extraction of CMC segments. $C M C$ ring segments are easily extracted from flat plates, which show a high rate of inherent material quality and reproducibility.

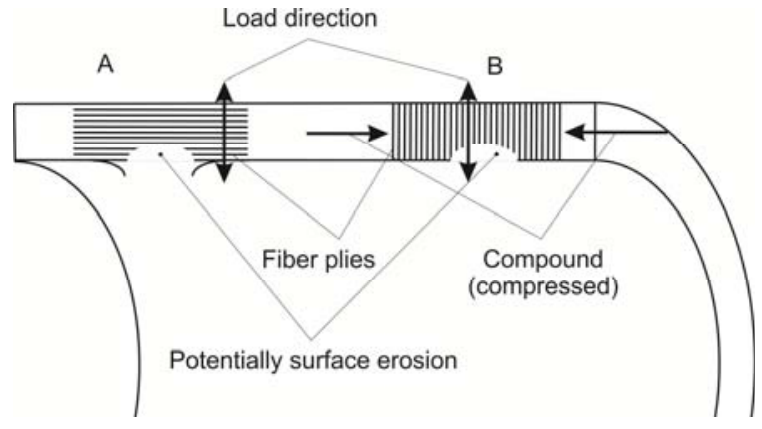

Figure 4. Surface erosion effects. The design approach of DLR (case B) reduces fatal failure at the surface, because load carrying fibers are only shortened.

flow characteristics are of substantially higher importance. In form of a fine grading of the ring properties along the inner hot gas wall, the designer can react locally against both thermal loads by the control of coolant diffusion along the chamber axis and thermochemical hot gas attacks. The latter should be considered well, because the combustion process generates varying hot gas formations along the flow axis. Close to the injector higher oxygen concentrations can be found, so that the wall material must resist high temperature plus oxidation. At this inner chamber position oxidic CMC materials can meet this requirement excellently combined with a slightly increased transpiration rate. More downstream the coolant diffusion can be reduced, and high temperature resistances as well as more thermal conductivities are effective. In particular the convergent nozzle section sees the highest heat flux loads, where e.g. the cooling can be significantly increased by higher material porosity and coolant permeability respectively.

The orthotropic mechanical characteristics of the inner liner material are oriented advantageously, because the fiber plies are arranged excellently in pressure load direction. There again the coolant flow resistance inside the porous wall shows its minimum along the plies. As an important result of this ply arrangement the coolant flows better in radial direction than in axial direction. These properties are of high advantage especially at the convergent nozzle section, where the pressure gradients inside the wall initiate a disturbing wall-inherent coolant flow deflection. To counteract this effect, the fiber plies create a kind of stabilizing guidance faces for the coolant diffusion.

A further significant advantage of this design approach can be seen in the material-related effect, that in case of erosion at the inner wall surface, no critical interruption of the mechanical load flow occurs, but merely the adjoining ends of load carrying fibers will be shortened (figure 4).

\section{CFRP Load Shell}

Multiple criteria led to the decision for the use of a load carrying housing made of CFRP. The very first argument supporting this decision had been seen in its obvious light weight characteristic. In particular the consideration of upper stage engines turns weight savings to account. The very low density $\left(\rho=1.8 \mathrm{~g} / \mathrm{cm}^{3}\right) \mathrm{of}$ an adequate composite material, showing in parallel more than $1 \mathrm{GPa}$ of tensile strength, should principally be taken 


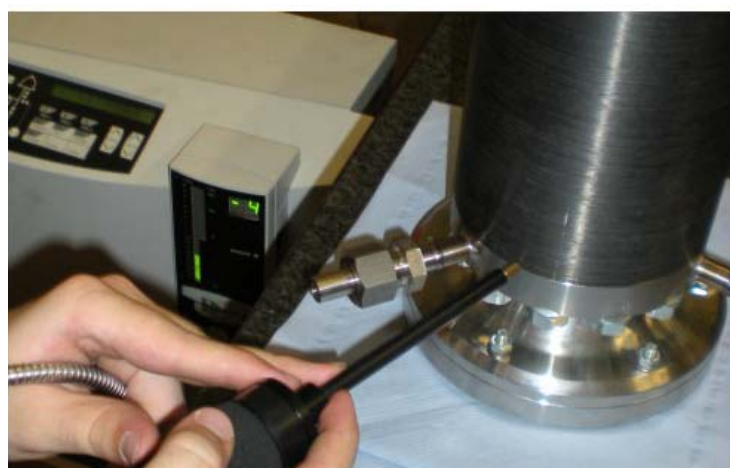

Figure 5. Leakage tests of the chamber housing.

The chamber assembly showed less than

$1 * 10^{-4}$ mbar $l /$ sec of leakage rate under 5 bars

He-pressure.

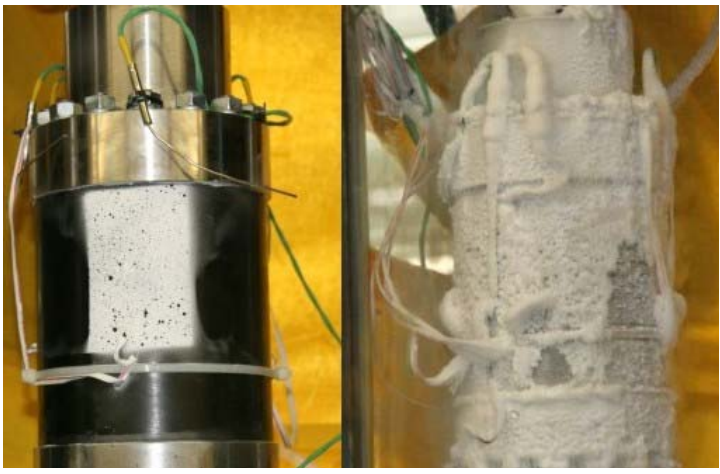

Figure 6. Tensile tests of CFRP housing. The CFRP housing had been tested in tensile direction both in ambient and cryogenic environment.

into account when searching such light weight solutions. The second argument supporting the use of CFRP is the low CTE. A general problem in the field of cryogenic rocket propulsion is the inappropriate fatigue behavior, caused by extreme thermal load cycles and high CTE values of the used metals. Reducing thermo mechanical loads is doubtless of high advantage. The measured CTE of the CFRP housing amounts about $\alpha=6^{*} 10^{-6} 1 / \mathrm{K}$ in our case. As manufacturing process of the CFRP body the VARI-method was chosen, using HTA fibers and epoxide resin as composite components.

The major challenge concerning the use of CFRP as a candidate for cryogenic rocket thrust chamber housings can be seen in the liquid hydrogen tightness. The representative requirement with respect to the operation at the rocket test benches is given by a leakage level of $1 * 10^{-3} \mathrm{mbar} 1 / \mathrm{sec}$ (Helium, at 5 bar of gas pressure). As in figure 5 , to target the test qualification, a stable level of $1 * 10^{-4} \mathrm{mbar} 1 / \mathrm{sec}$ could be proved around the whole thrust chamber assembly at any time. The critical areas were located at the interface seals. "Saint Gobain Omniseal products" have been proved as seal for the combination of metal and CFRP in LH2 environment and show further promising improvement potential for this application.

The CFRP shell itself based on a thermoset material matrix and ranged far below $1 * 10^{-5} \mathrm{mbar} 1 / \mathrm{sec}$. The leakage tests had been conducted both before and after cryogenic loading without any difference in the leakage ratios.

Additionally mechanical qualification tests had to be performed. Firstly the chamber pressurization (using water) up to more than 120 bars of inner pressure showed multiple times an excellent mechanical behavior of the integrated chamber assembly.

Further-on a tensile test pre-qualification (figure 6) had to be performed. Using an electromechanical tensile test facility (type Zwick, $10 \mathrm{kN}$ of maximum load) several tensile tests could be conducted under both cryogenic (LN2, $77 \mathrm{~K}$ ) and ambient conditions. As one important result the integrity of the homogeneous hollow-cylindrical CFRP structure could be proved for the thrust chamber application.

\section{Mechanical Interface between Metal and CFRP}

One of the significant structural innovations of DLR's integrated fiber reinforced thrust chamber system can be seen in a new kind of bolt interface. A variety of design evaluations concerning an adequate interface solution resulted finally in the bolt interface, described in the following. Basically the thermo mechanical compatibility of the different materials had to be taken into account. Hereby a selection of three specific approaches had been investigated preliminarily (figure 7):

1) Threaded metallic bolts, bonded into the front edges of the CFRP cylinder.

2) Key connector for standard CFRP-linkages.

3) Asymmetric metallic clamp, hooked into each skin surfaces, into both CFRP-skin surface and metallic flange skin surface respectively. 

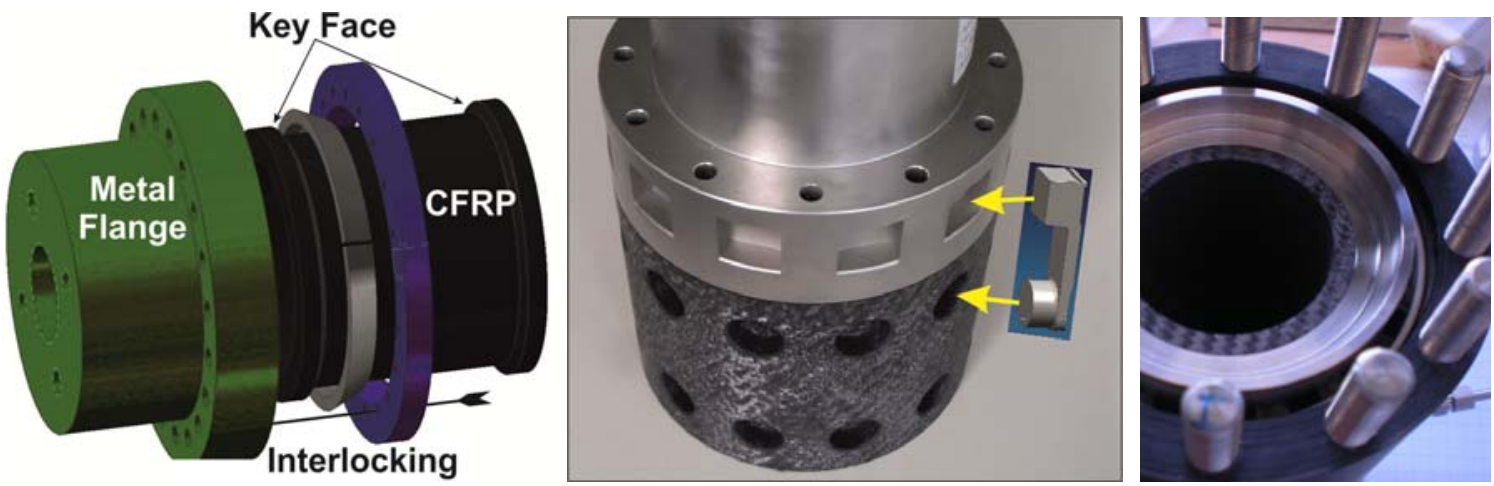

Figure 7. Mechanical interface selection. Key connector (left), asymmetric clamp interface (middle), bolt interface (right),

The key connector had been investigated first. An adequate basic fiber lay-up of the CFRP tube had been defined before and optimized by structural simulations. Because of diverse work specific restrictions the initial design approach of the CFRP body showed an easy lay-up method without changes of the fiber directions (figure 8). For this reason the bonding overlap of the load carrying CFRP shoulder had to be well-dimensioned. The key-shaped contact face showed the optimal angle of slope at a value of $\beta=30^{\circ}$, considering friction effects and the contact pressure per unit area.

Several static load tests have been performed demonstrating the design functionality. They showed in each case sufficient safety margin even if the weak shoulder version is applied. In the following some important results of those verification test activities will be described.

Tensile tests at ambient and cryogenic temperatures have been conducted using an electromechanical test machine mentioned before. Considering required inner combustion chamber pressures of 150 bars, a maximum tensile load of $250 \mathrm{kN}$ at the sample had to be proved

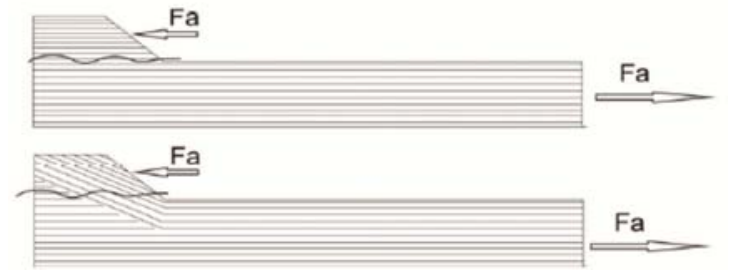

Figure 8. Two different shoulder designs of the CFRP key connector. Shoulder without change of fiber direction (upper), shoulder showing changes of fiber direction (lower). (figure 10). Firstly tests under ambient temperature environment had been performed. Of course the cryogenic test was of higher interest, but it also requires exponentially more effort for the preparation, why this kind of test was dated at last. The cryogenic test was combined additionally with a failure investigation so that this final test sequence showed as last load peak the failure (figure 10). Before starting the mechanical load phase the structure had to be cooled down completely by filling the tube with liquid nitrogen. To have all the time the temperature control at relevant structure regions multiple thermocouples were applied at interesting positions of each structure component. As in figure 9, the test sample and the corresponding temperature courses are represented. An interesting effect could be observed during the precooling phase: After about $3200 \mathrm{~s}$ the gaseous boundary layer between liquid nitrogen and the inner CFRP wall surface collapses exactly at that time when the inner surface temperature reaches the level of physical phase transformation. From that point on the liquid phase have direct contact to the CFRP material and the measured solid temperature decreases consequently, showing accordingly a rapid decrease of the solid temperature. All in all the pre-cooling phase takes most the time for one test shot. 

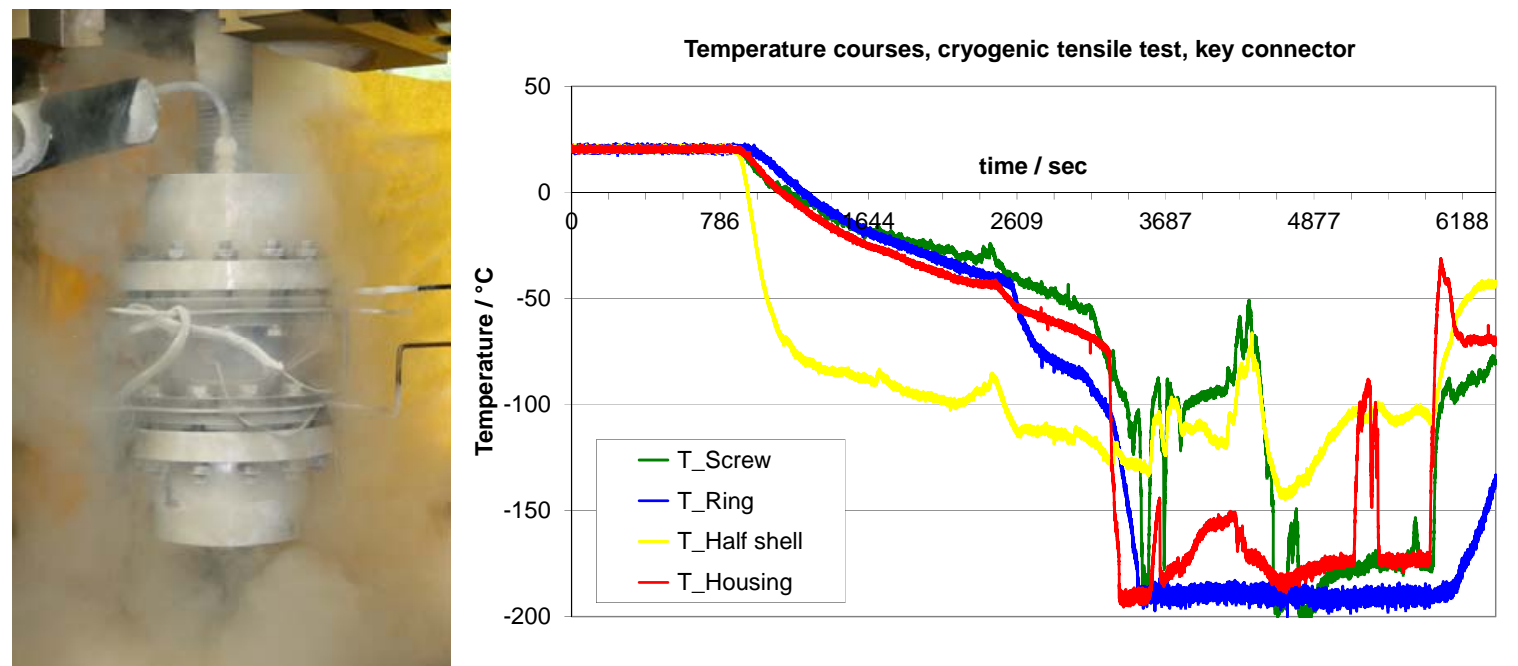

Figure 9. Key connector interface. Cryogenic tensile test at $77 \mathrm{~K}$ (left), strains of CFRP housing in circumferential direction at ambient temperature and under inner water pressurization (right).

The interesting mechanical test phase showed three significant load peaks, divided into different ramps and steps leading into the final failure ramp-up. The residual failure load amounted to $350 \mathrm{kN}$ corresponding to a safety factor of $\mathrm{S}=1.23$.

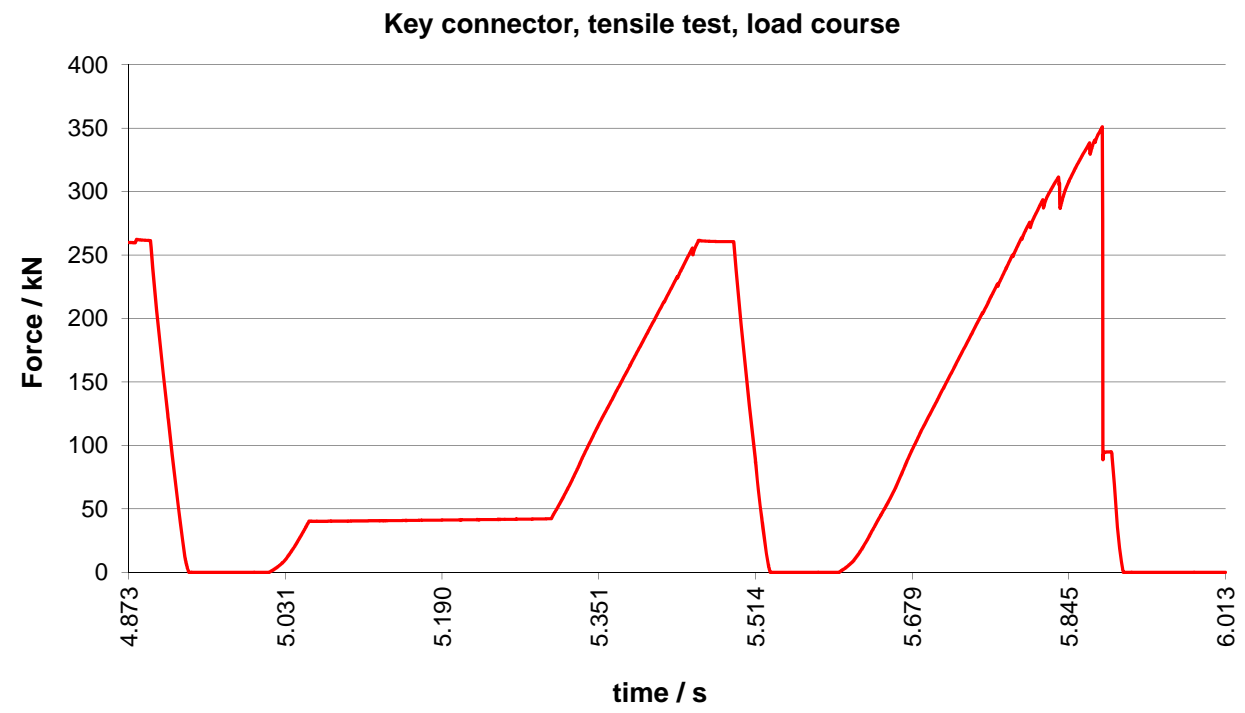

Figure 10. Key connector interface. Cryogenic tensile test at $T=77 \mathrm{~K}$.

To indicate the original pressure loading at the system, the structure had been pressurized also by water. The pressure ramped up to a maximum value of $p=300$ bar (figure 11). To demonstrate the structural integrity, strains were measured, centered at the outer surface of the load shell (figure 12), which represents the tallest and weakest cross section of this component. Axial as well as circumferential strains range up to maximum $1.8 \mathrm{~mm} / \mathrm{m}$, which is significantly lower than $3 \mathrm{~mm} / \mathrm{m}$ (approximately half of this value), representing the usual limit for CFRP in this case. Considering the current safety factor of 1.23 at the maximum load, this strain reserve represents additional safety. 

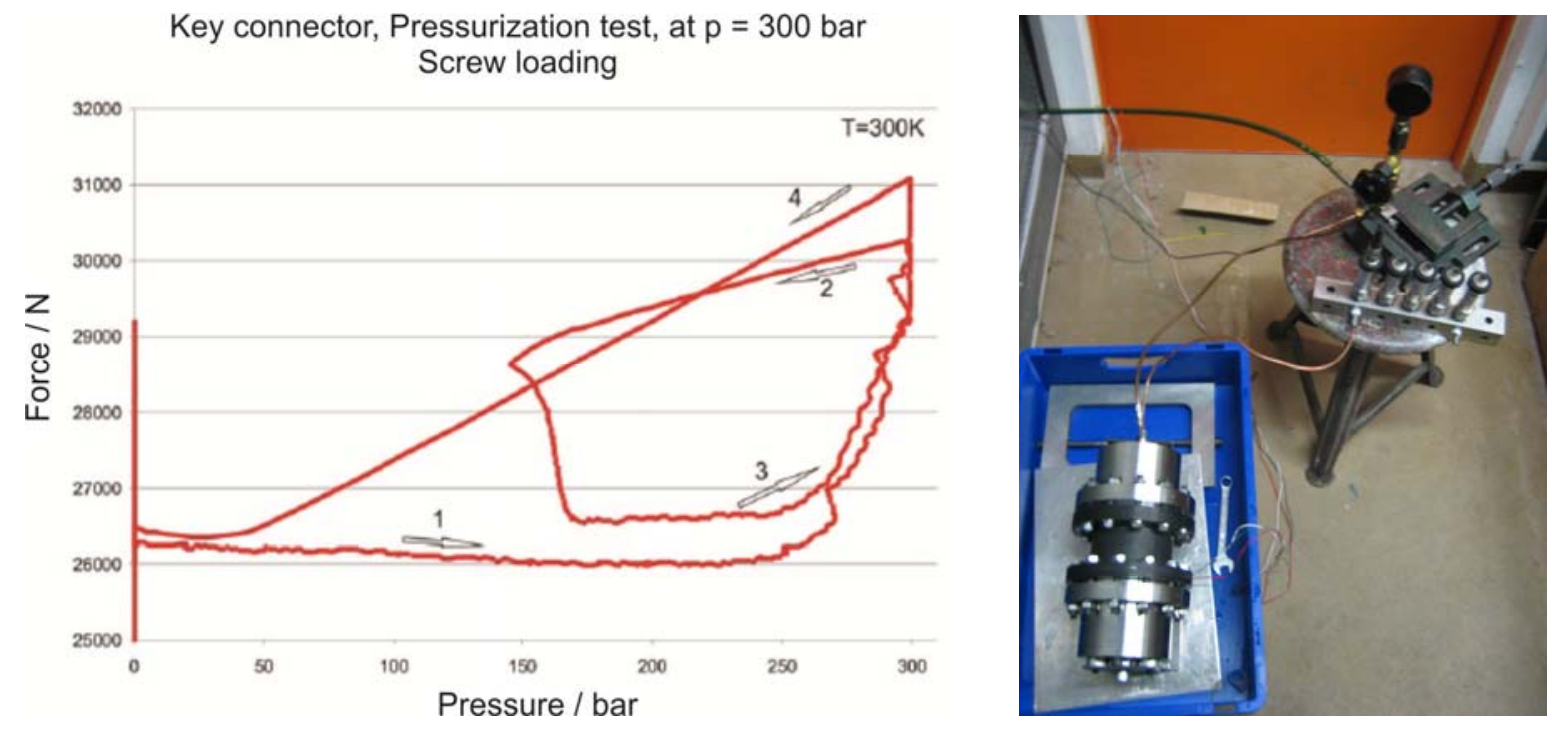

Figure 11. Key connector interface. Water pressurization test of the CFRP tube up to $p=300$ bar (right). Load course at one representative connecting screw during one complete load cycle (left).

The analytical dimensioning of the connecting screws resulted in a maximum acceptable load of $330 \mathrm{kN}$. The maximum load derived from the pressure test amounted to marginally more than $310 \mathrm{kN}$, as given in figure 10 , showing one complete pressure load cycle. This means too low safety and requires additional design optimization!

The final cryogenic failure test showed the expected shear failure, as given in figure 13 . Hence one obvious improvement aspect should be the second shoulder design, showing changes of the fiber direction, as given in figure 8 , with respect to further optimizations of the current system. But in general the corresponding effort of future keyconnector development seems to be more appropriate specifically focusing on large scale thrust chamber systems, in which the deadweight ratio should decrease.
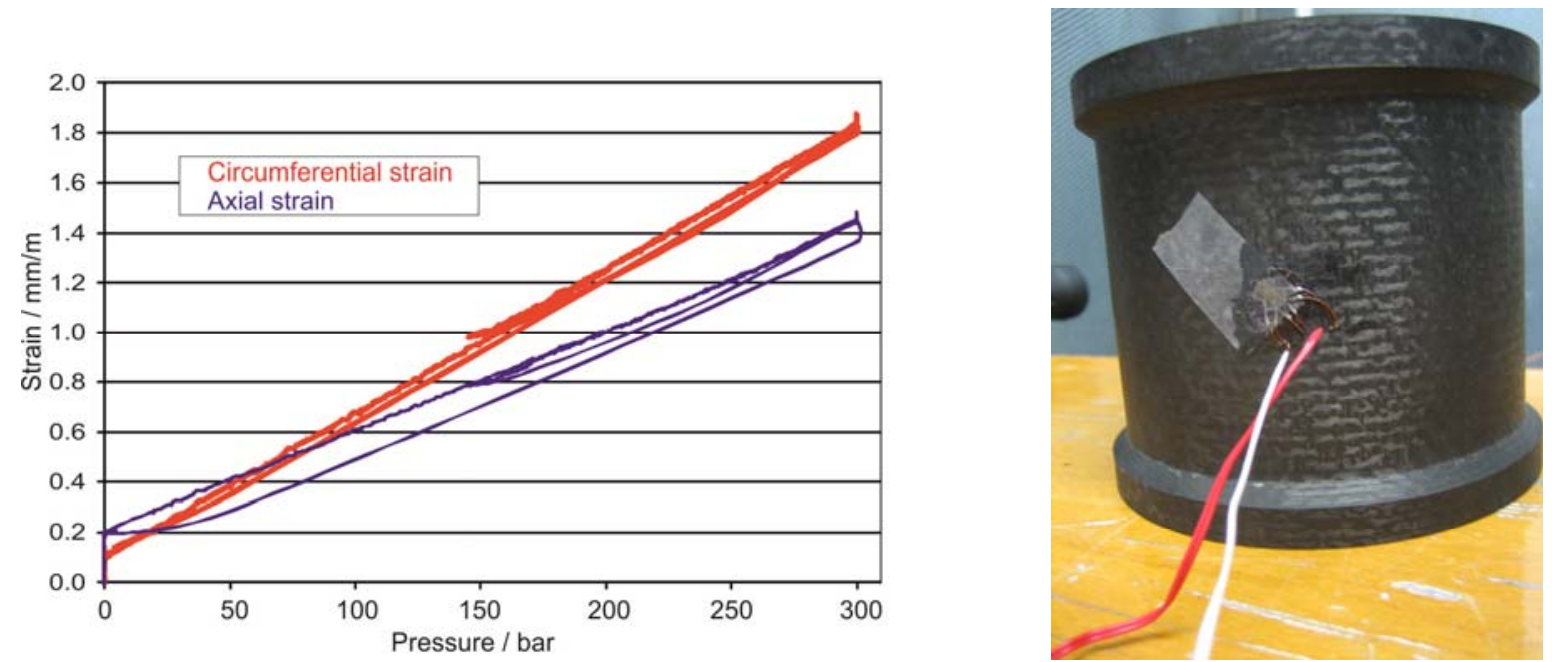

Figure 12. Representative strain curves of the key connector CFRP tube. Water pressurization test of the CFRP housing at a pressure of $p=300$ bar. Linear strain courses show maximum values of about $1.8 \mathrm{~mm} / \mathrm{m}$ ranging far below the acceptable limit of $3.0 \mathrm{~mm} / \mathrm{m}$. 
At the point of decision, which concept to choose, one came to the result that the key connector, which is normally a robust standard CFRP linkage, should be excluded in this stadium of research. Although this generally reliable joining method is absolutely usual in the field of fiber reinforced engineering, in this case it shows the need of bulky clamping rings, a fact, which is accompanied by additional high weight and the need of sufficient available space.

The second interface solution was represented by a clamp system, as in figure 7 (middle) and figure 14 (top). The basic idea is a joining method, which shows similarity to a hybrid joining system used in the field of wind converter applications and shall benefit from experience of high load transitions (figure 31). Detachable connections are desired, using easy opening mechanisms, which don't require complex mounting processes. The widespread method shows an axial strain bolt inserted into the fiber reinforced plastic tube from the front edges. At the end position of the bolt inside the plastic structure, the plastic housing surface shows a relatively large cylindrical cross hole, which assimilates a metallic cross bolt including a threaded hole in diametrical direction related to its own geometry. The threaded strain bolt will be turned into the crossing locking cylinder. The loaded system transfers the operational load at the cylindrical contact area between metallic cross cylinder and the wal of the CFRP bore hole. In contrast to this joining system the combination of axial bolt and radial locking cylinder should be prevented because of its complexity. At first view it seemed to be principally easier, inserting clamps into holes at the outer housing structure, as given in figure 7 (middle) and then locking them. This represents an asymmetric design approach.

But in spite of kinematic constraints in form of multiple mechanical blocks at critical structure sections between clamp and housing structure it is elaborate in the practice to avoid clamp-bending because of its asymmetric shape. First evaluations seemed to be promising but later simulations as well as mechanical tests showed distinctively the bending sensitivity inside the clamp, which lowers extremely the load-bearing capacity compared to purely tensile loaded bolts (figure 14, middle). A second effect, which reduces the load-bearing capacity, is the occurrence of local mechanical surface pressure peaks (figure 14, bottom).

Since the stresses exceed significantly the admissible loads of the clamp material, this specific approach will not be pursued further at the moment. Future changes to a loadsymmetric clamp system will be interesting, with respect to CMC interface applications.

The third approach of mechanical interface is represented by the so-called bolt-interface. It consists of threaded metallic bolts, which are continuously bonded by resin into threaded holes at the front edges of the CFRPring (figure $16 ; 17$ ). Due to former investigations, such

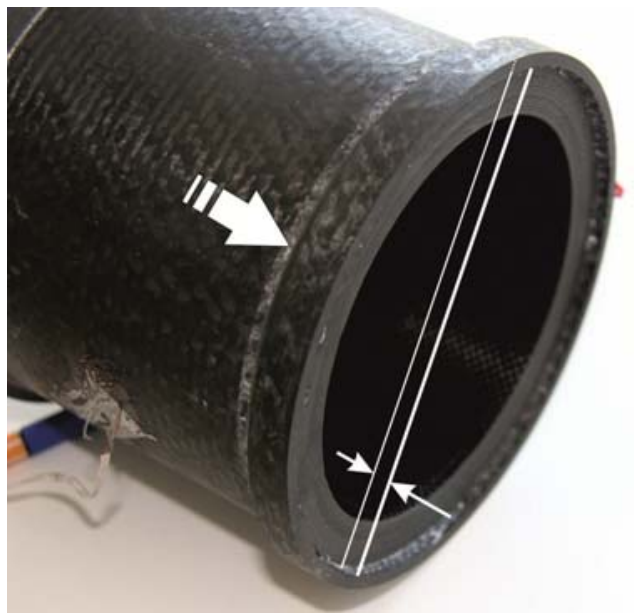

Figure 13. Key connector interface - Water pressurization test of the CFRP tube up to $p=300$ bar (right). Load course at one representative connecting screw during one complete load cycle (left).
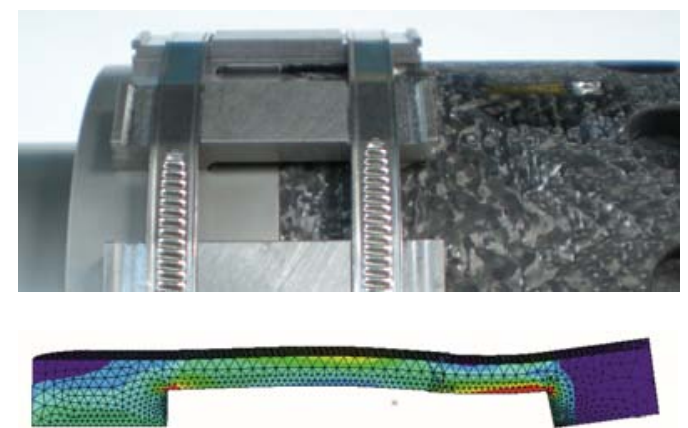

$$
\text { Stress (von Mises) }
$$
$\mathrm{MPa}$
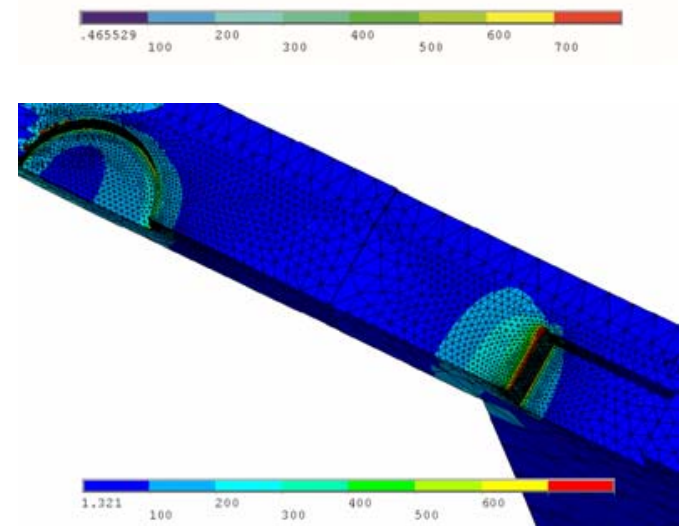

Figure 14. Asymmetric clamp interface. Test set (top), high bending moments close to the main contact face (middle), very high surface pressure (bottom). 
bolts, which were bonded into flat laminates lead to very rapid delamination. But in this case the closed ring shaped structure makes sure, that the interface retains itself.

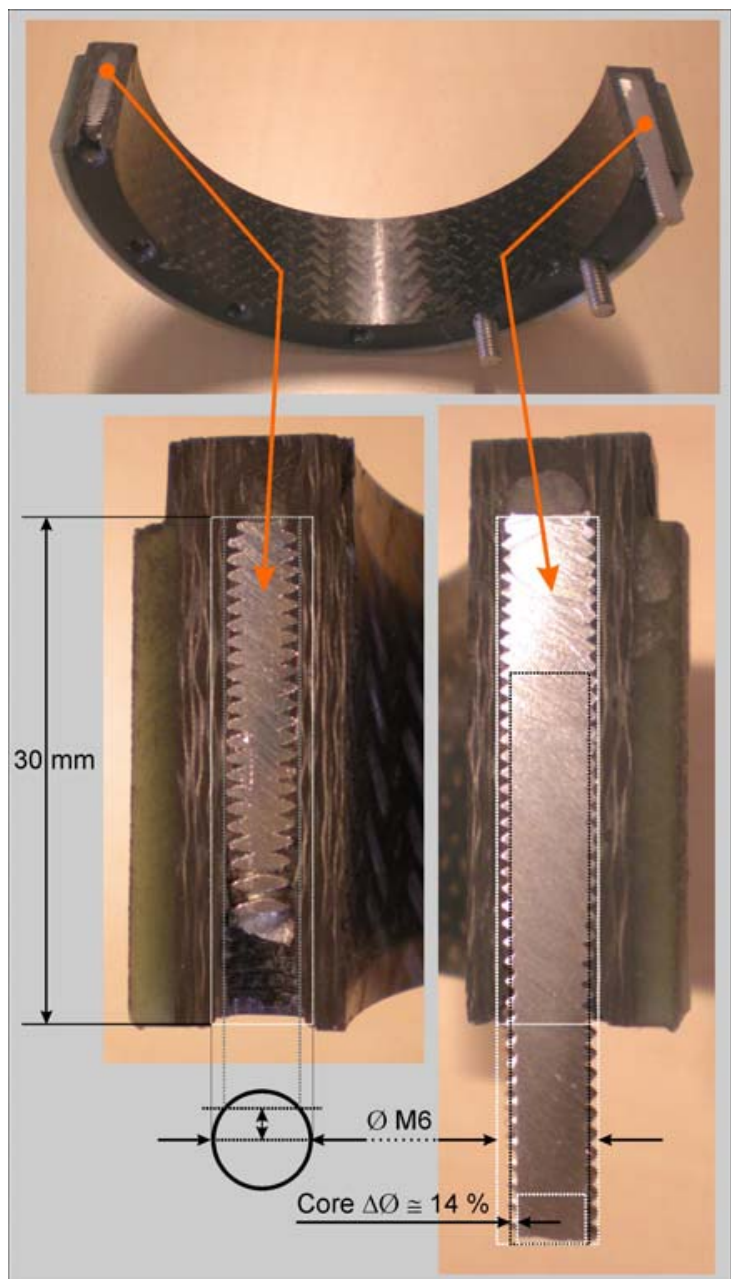

Figure 16. Bolt interface, failure pattern .Lateral contraction of the bolts after failure, given by two representative bolt cuts.

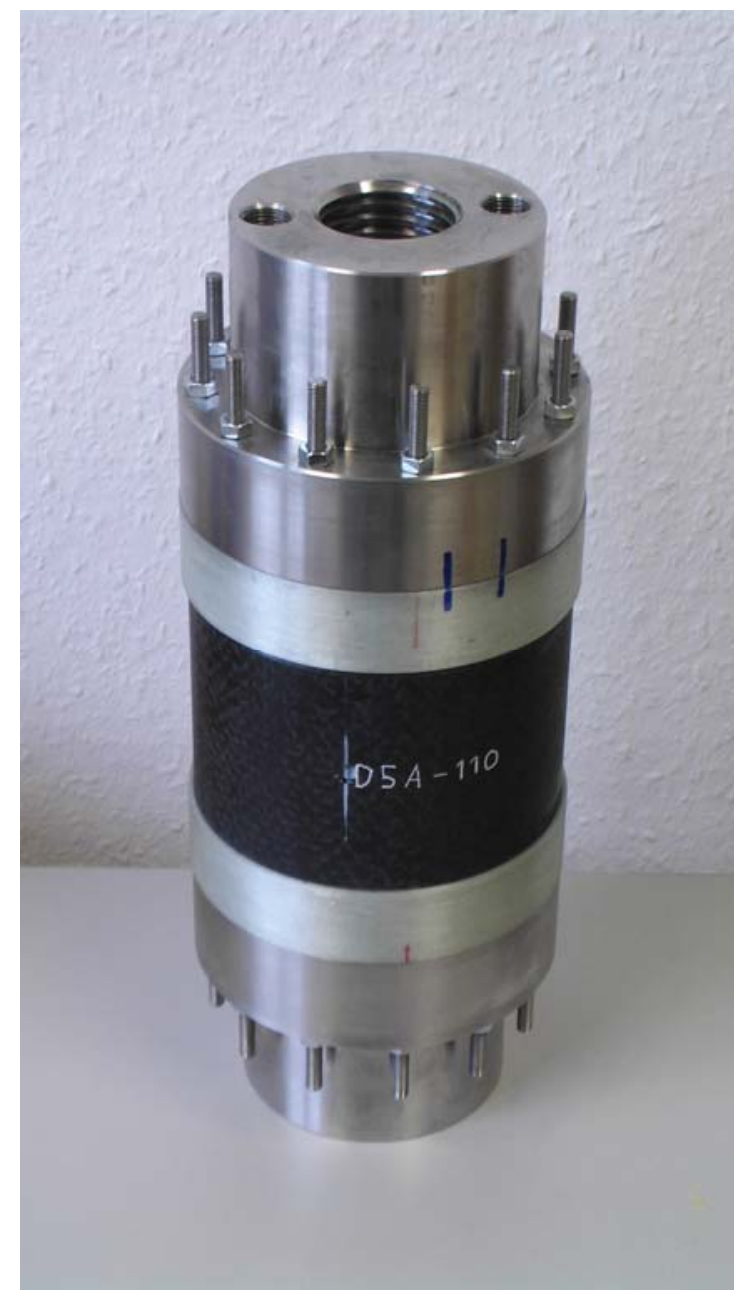

Figure 15. Bolt interface, test specimen. Test specimen for tensile tests (row of $12 \times$ M6 screws).

Multiple tests in the electromechanical tensile test machine have been conducted under a variety of different technical requirements. Firstly small CFRP tubes, showing $d_{\text {outer }}=70 \mathrm{~mm}$ of outer diameter, $1=100 \mathrm{~mm}$ of length and $\mathrm{s}=10 \mathrm{~mm}$ of thickness, were equipped with threaded bolts having $\mathrm{d}=6 \mathrm{~mm}$ of diameter and a standard metric thread. At the beginning standard metal bolts (strength class: $\mathrm{Rm}=800 \mathrm{MPa}$ ) were applied, later the highest strength class $(\mathrm{Rm}=1200 \mathrm{MPa})$ was used. The results showed invariably no failure at the interesting interface area between metal bolt and CFRP material. In all cases the effect was pure metal failure outside the connection area. This promising result encouraged further investigations, using CFRP shells showing the original size relating to the planned test application. Secondly one larger CFRP tube showing $\mathrm{d}_{\text {outer }}=110 \mathrm{~mm}, 1=150 \mathrm{~mm}$ and $\mathrm{s}=12 \mathrm{~mm}$ were equipped by rows of 12 screws at the front edges (figures 15). In this case the screws showed the same size and thread geometry as in the previous tests, because the relation between the metallic thread geometry and the inherent structure of the fiber lay-up had declared as degree of freedom in this system, which should not see any change in the transition of the tube sizes. These tests have been performed for the first time both in ambient and cryogenic $(\mathrm{T}=$ $77 \mathrm{~K}$ ) environment. 
Figure 18 shows a triple of test sets. Firstly one cryogenic test had been conducted including three hysteresis cycles. Secondly a similar load spectrum had been applied under ambient conditions and at last a cryogenic test run including the final failure test had been performed. As given in the figure, one can see that after one first start-up process the following three nominal load cycles are almost congruent without significant deviations. This result demonstrates in all three cases reproducible and stable linear-elastic behavior. The slight increase of the absolute elongation (start value $0.75 \mathrm{~mm}$ ) as well as the slightly spreading of the third hysteresis allows the interpretation of an initial settling process inside the structure (in particular the bolt interface). The reduction of the maximum elongation values, comparing the second and the third tensile test set, indicates on the one hand the reproducibility in the measurement of the material characteristic and on the other hand the stable linear-elastic behavior without further structure degradation. The third test set is also given in figure 18 . One can see that the three nominal load peaks ranges far away from the fracture load, what gives good evidence of the later functionality in rocket test environment.

The metallic creeping up to fracture of the screws led finally to more than $8 \mathrm{~mm}$ elongation per screw, which is again and again very impressive to observe. The dimensioning load of this bolt interface set-up (operational force $\mathrm{F}=100 \mathrm{kN}$ ) wasn't yet suitable for the investigation under hot gas conditions at the rocket test bench.

With respect to the later hot gas tests, the size of the threaded bolt changed from $6 \mathrm{~mm}$ to $\mathrm{d}=10 \mathrm{~mm}$ of outer diameter, whereas the thread slope of $1 \mathrm{~mm}$ was approximately fixed, due to the intension, not to change significantly the interaction geometry between the pitch of screw thread and the inner lay-up structure of the CFRP compound.

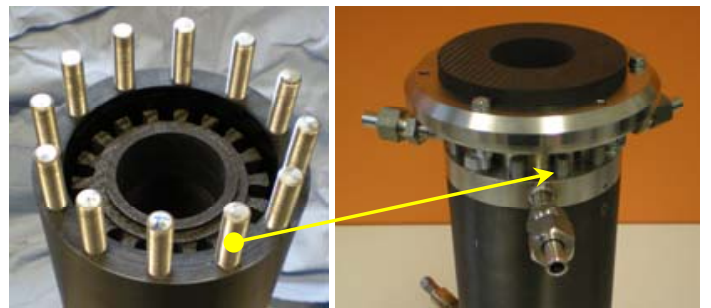

Figure 19. Bolt interface, nominal design. Rows of 12 bolts $(d=10 \mathrm{~mm})$ at the CFRP front edges.

Due to the final load bearing capacity of the chamber set-up for the hot gas tests (figure 19), the nominal bolt interface design showed at last rows of 12 bolts at each CFRP front edge. Chosen was the $10 \mathrm{~mm}$ - bolt design mentioned before. Under this boundary conditions the thrust chamber could carry the nominal axial load of 250 $\mathrm{kN}$, showing at least a safety margin of $\mathrm{S}=1.2$. With this final hardware tensile tests (similar to the tests using the

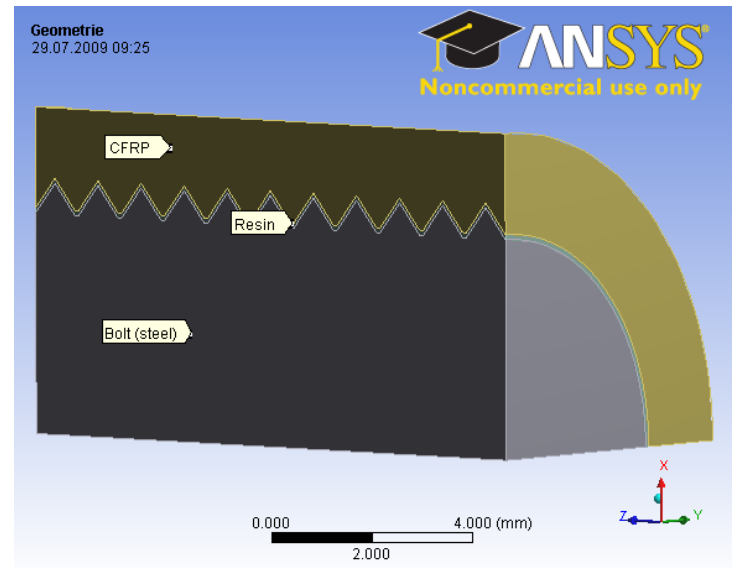

Figure 17. Bolt interface, design principle. Three separate components, metallic bolt, CFRP structure and resin layer represent the interface system.

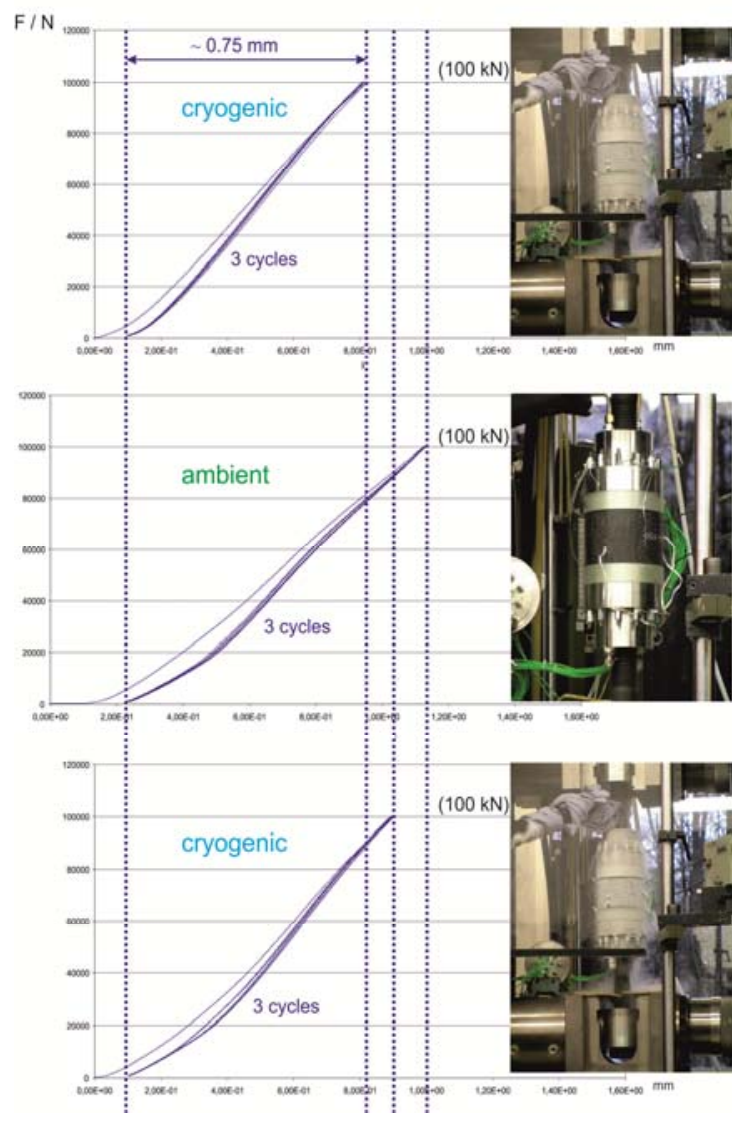

Figure 18. Bolt interface, hysteresis tests $(12 \times$ M6 bolts). Three separate hysteresis test series including ambient and cryogenic test environments. Three load cycles per test.

American Institute of Aeronautics and Astronautics 
M6 bolts, figure 20) up to $200 \mathrm{kN}$ tensile force have been performed. In this case leakage tests (figure 5) have been conducted successfully before and after cryogenic and ambient tests.
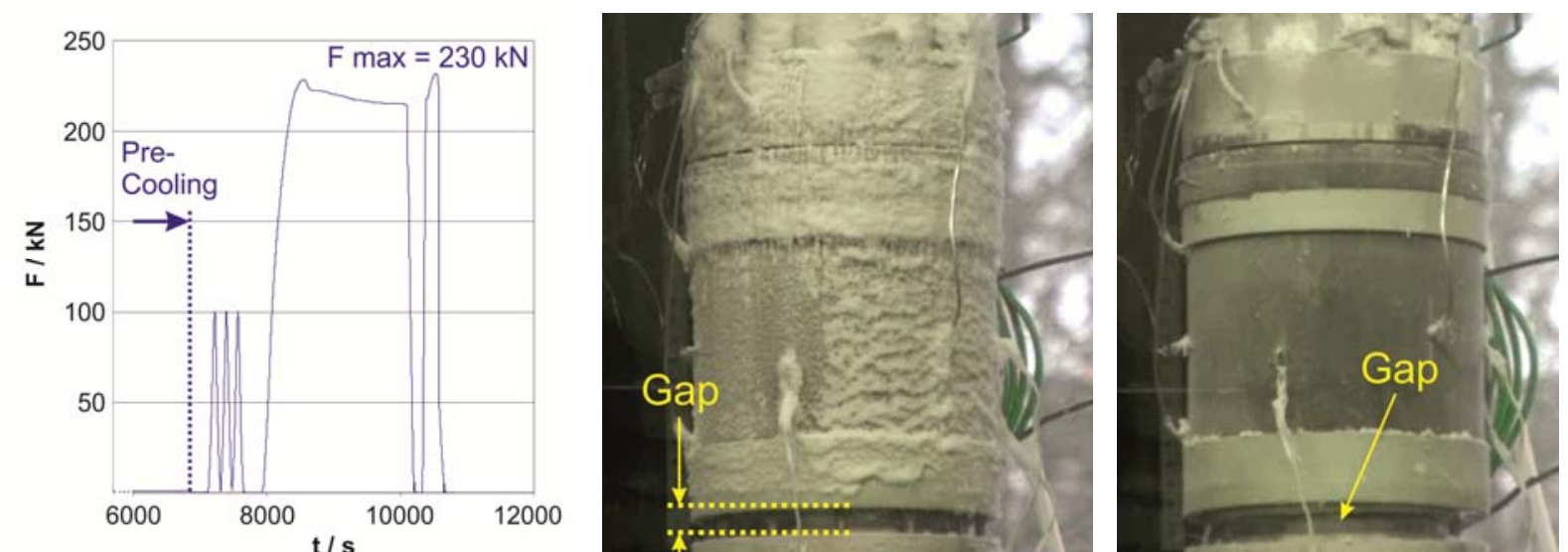

Figure 20. Bolt interface, failure test (12 x M6 bolts). Load course incl. pre-cooling (left), highly tensile loaded sample directly before failure (middle), sample directly after failure (right). Because of creeping the $100 \mathrm{~mm}$ long bolts had been elongated up to $8 \mathrm{~mm}$. The rupture shock has shaken off the snow at the specimen surface.

Before starting the analytical investigation, the material characteristics had been assorted. Table 1 and 2 show the material characteristics of the three relevant interface components, CFRP, resin layer and threaded metallic bolt (figure 17). As the adequate bolt material A4/80 stainless steel was chosen, that shows a strain-hardening capability under cryogenic operational conditions.

Table 1: Material characteristics of CFRP, used in the bolt-interface analysis.

\begin{tabular}{cccc}
\multicolumn{5}{c}{ CFRP } \\
\hline $\mathrm{E}_{\mathrm{xx}}$ & $9650 \mathrm{MPa}$ & $v_{\mathrm{xy}}$ & 0,03 \\
$\mathrm{E}_{\mathrm{yy}}$ & $88420 \mathrm{MPa}$ & $v_{\mathrm{xz}}$ & 0,03 \\
$\mathrm{E}_{z z}$ & $88420 \mathrm{MPa}$ & $v_{\mathrm{yz}}$ & 0,3 \\
$\mathrm{G}_{\mathrm{xy}}$ & $16000 \mathrm{MPa}$ & $\alpha$ (fibre) & $6 \mathrm{e}-61 / \mathrm{K}$ \\
$\mathrm{G}_{\mathrm{xz}}$ & $16000 \mathrm{MPa}$ & $\alpha$ (cross & $15 \mathrm{e}-61 / \mathrm{K}$ \\
$\mathrm{G}_{\mathrm{yz}}$ & $15000 \mathrm{MPa}$ & section) &
\end{tabular}

Table 2: Material characteristics of steel and resin adhesive, used in the bolt-interface analysis.

\begin{tabular}{cccc} 
Steel & \multicolumn{3}{c}{ Resin } \\
\hline $\begin{array}{c}\text { Steel type } \\
\begin{array}{c}\text { Strength } \\
\text { class }\end{array}\end{array}$ & A4 & Resin type & Epoxide \\
E & $200000 \mathrm{MPa}$ & & \\
$\mathrm{Rp}$ & $600 \mathrm{MPa}$ & $\mathrm{E}$ & $3000-3300$ \\
$\mathrm{Rm}$ & $800 \mathrm{MPa}$ & $\mathrm{Rp}$ & $150 \mathrm{MPa}$ \\
$v$ & 0,31 & & \\
$\alpha$ & $1,7 \mathrm{e}-51 / \mathrm{K}$ & $v$ & 0,3 \\
& & $\alpha$ & $5 \mathrm{e}-51 / \mathrm{K}$
\end{tabular}

12

American Institute of Aeronautics and Astronautics 
The structural simulation of the bolt interface included already the original bolt geometry for the following hot gas tests. Those bolts showed $10 \mathrm{~mm}$ of diameter and $100 \mathrm{~mm}$ of length. Furthermore the thread had been adapted to the similar slope compared to the M6 bolts, so that the contact pattern between the threaded bolt and the threaded CFRP substructure was similar to the tests.

Indeed the maximum stress exceeds the load limit of the plastic structure in one tall section at the end of the interface. But the corresponding local material failure should be able to be accepted, because along the continuous contact area there is sufficient residual load-bearing capacity. In the rear area of the interface the residual load will be distributed more uniformly so that the entire loadbearing capacity can be guarantied. This fact could be approved by the strengths of the past empirical experience. In the situation of screw failure, initiated by material creeping effects, the metallic bolt takes a lateral contraction, as can be seen in figure 16. This effect leads to de-bonding between metal and CFRP substructure exact in this region, where the maximum stresses occur. But apart from this, at the rear contact area sufficient load carrying contact quantity remains, so that the general load-bearing capacity of the bolt interface isn't affected actually.

As in figure 21, one further interesting effect is represented. In cold operation environment, thus, when the major load phase of the thrust chamber starts during hot gas operation, almost the continuous contact area carries the load.

For the purposes of structural simulations at the overall chamber structure, the material characteristics given above have been used. In these simulations the bolt-interface was simplified by the replacement of a planar face contact. Furthermore the inner CMC liner was omitted and the mechanical compression load of the inner liner was simplified by applying one conservative axial load (about $10 \mathrm{kN}$ ), which was added to the inner gas pressure load. The

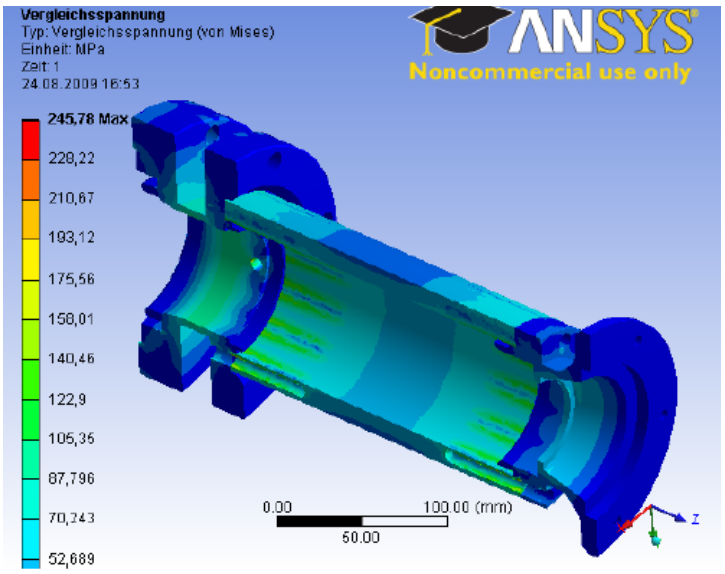

Figure 22. Analysis of the load carrying thrust chamber assembly. Stress distribution is undercritical at all components.
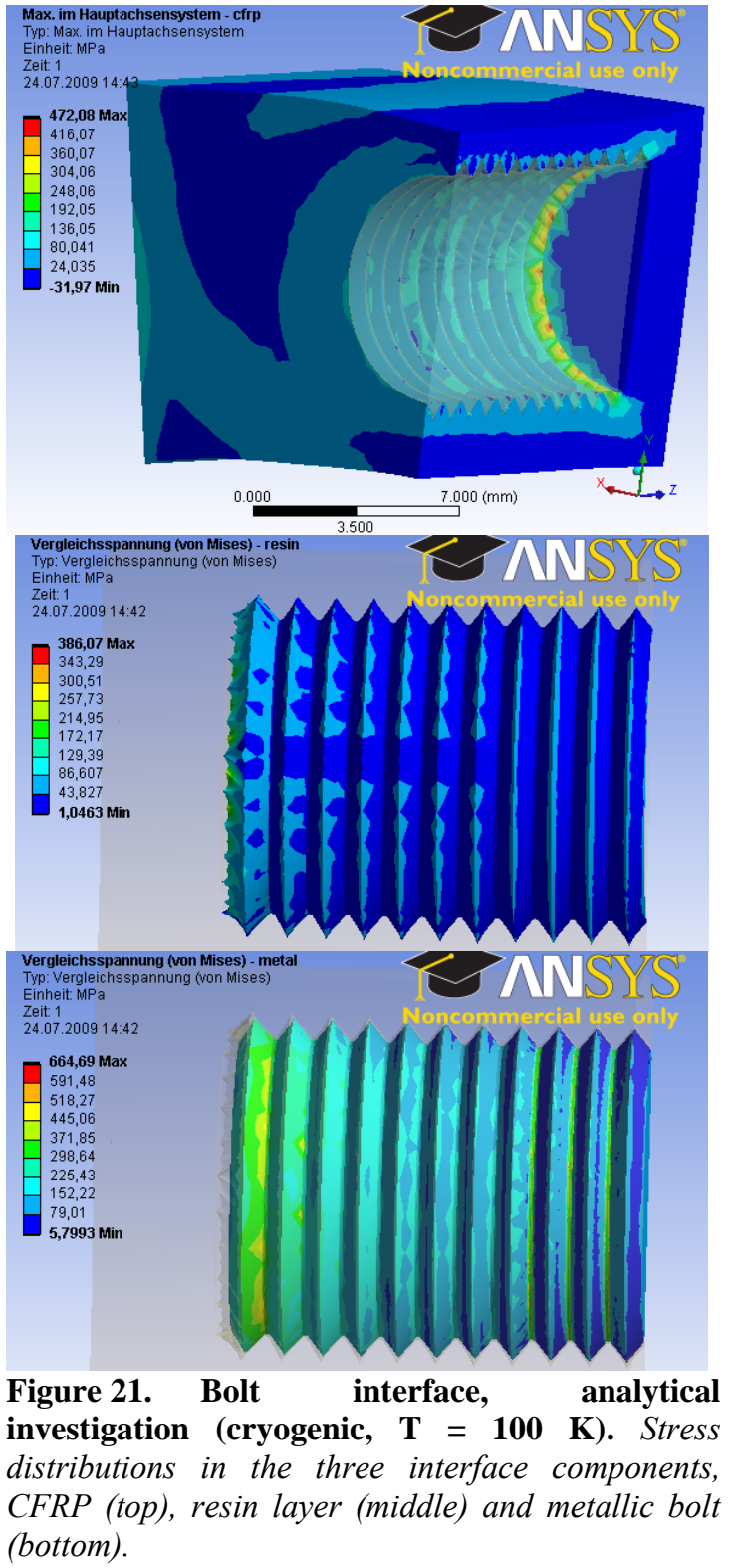

result of such a representative analysis is given in figure 22. The maximum stress of $\sigma_{\max }=246 \mathrm{MPa}$ appears at one single point at the CFRP, considering the stress limit of more than $\sigma_{\text {limit }}=500 \mathrm{MPa}$.

All in all the empirical and numerical investigations up to this point gave a good perspective to conduct the hot gas test program successfully from the structural point of view. 


\section{Hot gas tests at DLR's test benches for rocket propulsion technology}

In summer 2010 first high performance tests at a combustion pressure of $p=55$ bar, and using LOX / LH2 as propellants, had been conducted, at the European Research and Technology Test Facility P8 at DLR Lampoldshausen. The concept of the corresponding test hardware, the ST5-demonstrator (figure 23), had been
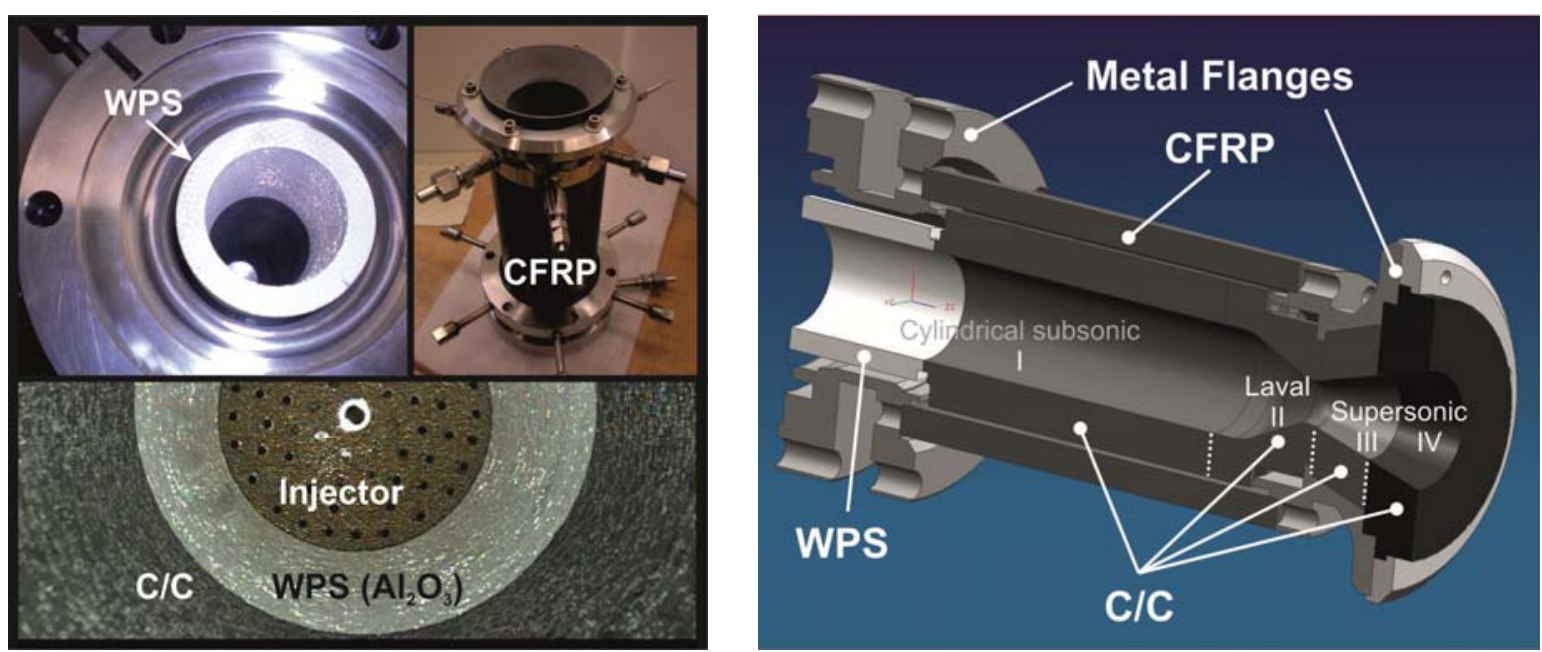

Figure 23. Test hardware. P8 configuration of the ST5-demonstrator (left, see also figure 1 and 24), showing two different CMC's at the inner liner position as well as the Vulcain nozzle contour (contraction ratio 2.5). Longitudinal section of the ST5 chamber (CAD-view, right), showing additionally an increased nozzle contraction ratio of 6.25 for test at the P6.1 test bench.

designed twice, applicable both for tests at the P8 test bench, using the Vulcain nozzle contour and for tests at the renewed P6.1 test bench, using the contraction ratio of 6.25 because of lower test bench performance. The design concept allows an easy replacement of the CMC nozzle set (three $\mathrm{C} / \mathrm{C}$ segments II - IV) corresponding to each

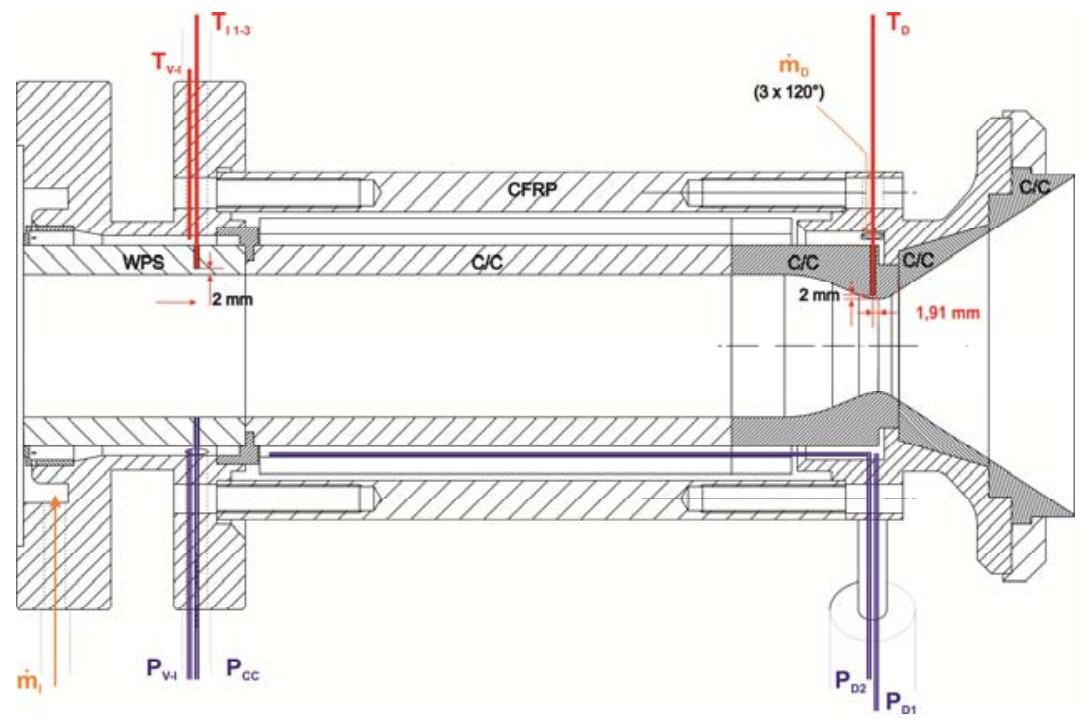

Figure 24. Measurement equipment. The demonstrator was equipped with thermocouples (red), pressure sensors (blue) and mass flow orifices (orange).

nozzle contour, remaining the cylindrical CMC components. The inner liner shows two separated coolant supplies. The first flow goes into the WPS-segment, the second one into the stack of C/C segments of zone I, II and III (figure 23 , right). Thus the cooled inner hot gas surface extends from the subsonic to the supersonic zone. If required the 
coolant supply of zone III can be blocked. The outer C/C segment at the down-stream end of the chamber (zone No. IV) is passively cooled.

From November 2011 until March 2012 the latest test campaign (MT5-A) happened at the renewed P6.1 test bench, using the chamber configuration as given in figure 23 (right) with the high nozzle contraction ratio. In this campaign the GH2 fuel ranged at a temperature level of about $100-150 \mathrm{~K}$, whereas the oxidizer (LOX) was in liquid condition. The chamber pressure amounted up to $\sim 65$ bars. Table 3 lists the number of tests performed with the ST5 demonstrator hardware. At the end of the two campaigns the load carrying chamber structure saw in total a number of 28 cryogenic thermal cycles, 10 cold pressure cycles of pressure levels between 40 and 65 bars. Besides the system's cooling efficiency ${ }^{1}$ could be proved by the demonstration of $\tau<10 \%$

Table 3: Test summary, ST5 demonstrator.

Test nomenclature

Nominal chamber pressure level/ bar Test duration / s

Number of tests (premature stop)

\section{KSK-ST5 Campaign (P8)}

Coldflow test

Run-In test

Hot-Run

MT5-A Campaign (P6.1)

Igniter test (without chamber)

Coldflow test

Run-In test

Hot-Run

\section{2}

20

60
20

20

$6 / 15 / 120$ $4\left(2^{*}\right)$

* unsuitable mass flow orifice

Finally some representative test results will be given. Figure 25 shows the sensor positions related to the nomenclature in the consecutive diagrams. Consequently the pressure loading during representative hot-runs of both campaigns is given by figures 26 and 27. According temperature courses are given by figures 28 and 29 . The abbreviations 'Z-N', 'I-O' and 'I-H' in the diagrams are the labels of 'igniter N2', 'injector O2' and 'injector H2'.
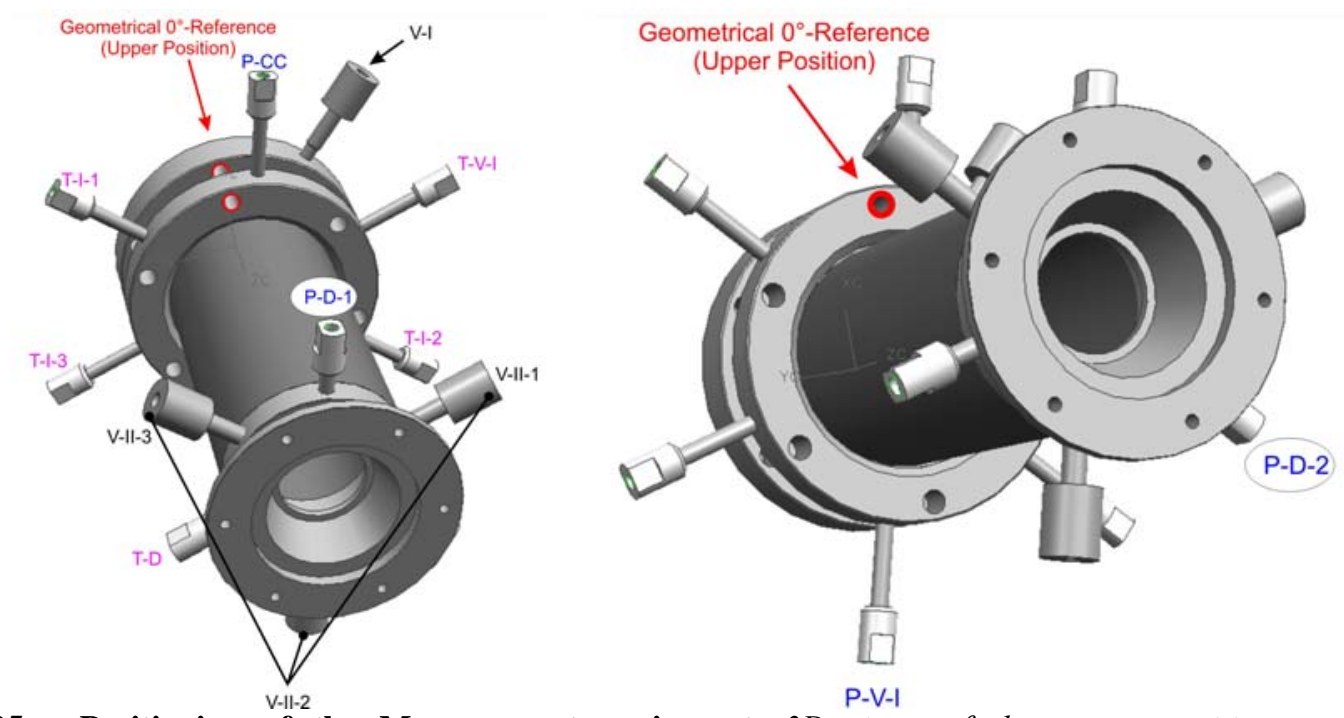

Figure 25. Positioning of the Measurement equipment. $3 D$ views of the sensor positions at the ST5 demonstrator. 
P8 - KSK ST5 Campain - 2010 Q2 - 04run2 Hotrun - Pressure Courses

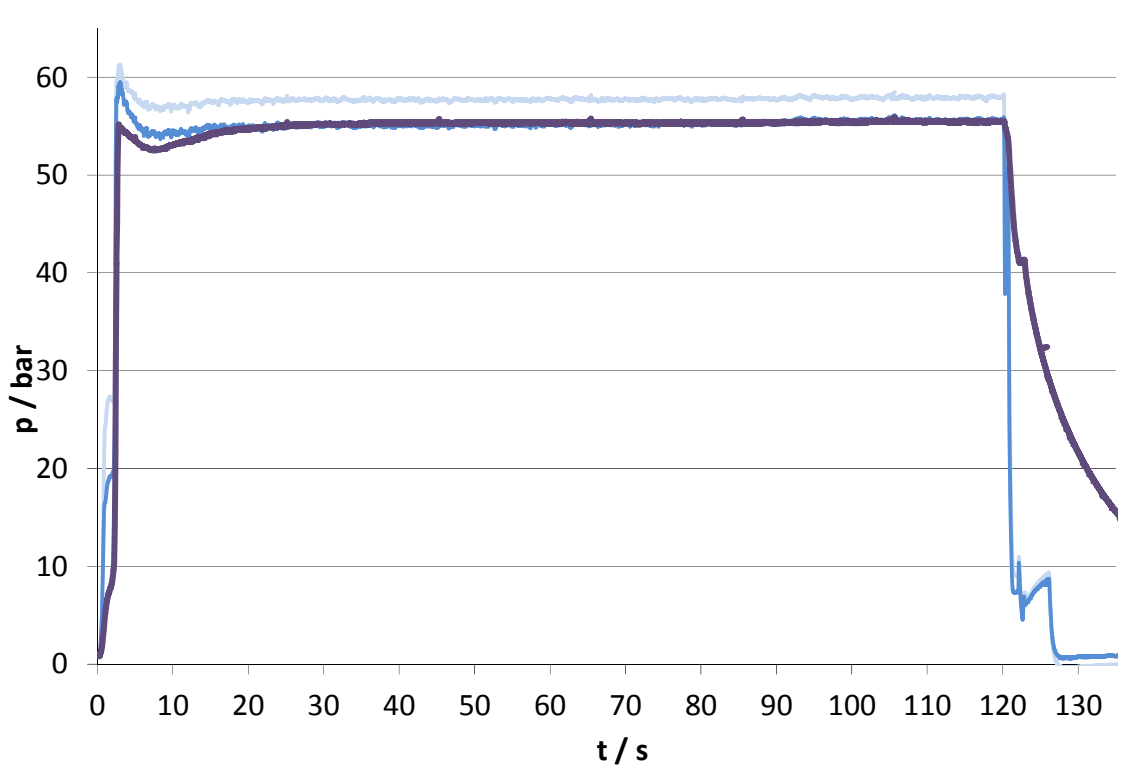

Test Configuration

$p_{c}=57 b a r$

$\tau=15,2 \%$

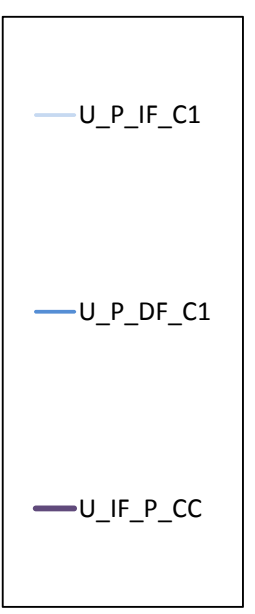

Figure 26. Pressure loading ST5 demonstrator, ST5 campaign (P8). Most representative 120 s long P8-hotrun at a pressure level of $p=55$ bar.

P6.1 - MT5-A Campaign - 2012 Q1 T06 - HOTRUN - Pressure Courses

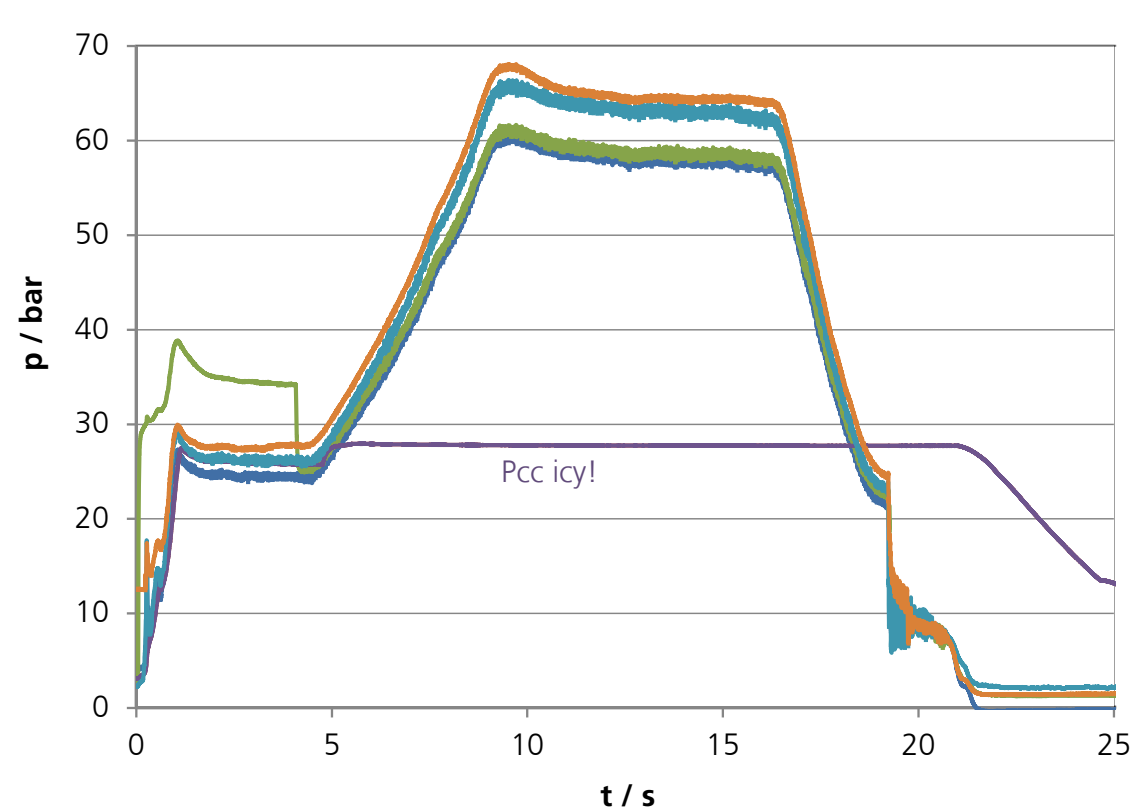

Test configuration

$\mathbf{p}_{\mathrm{c}}=\mathbf{6 0} \mathrm{bar}$

$\tau \rightarrow \mathbf{9 , 8 7} \%$

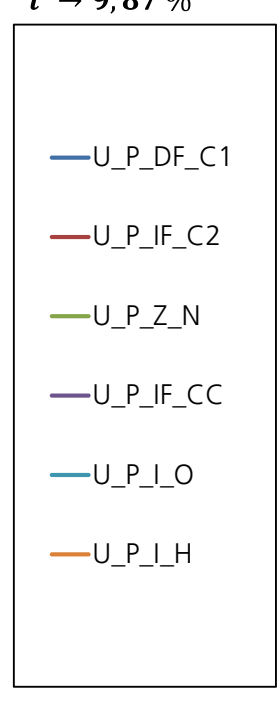

Figure 27. Pressure loading ST5 demonstrator, MT5-A campaign (P6.1). 20 s long P6.1-hot-run at a pressure level of $p=60$ bar after 15 seconds of pre-cooling. 
P8 - KSK ST5 Campain - 2010 Q2 - 04run2 Hotrun - Temperature Courses

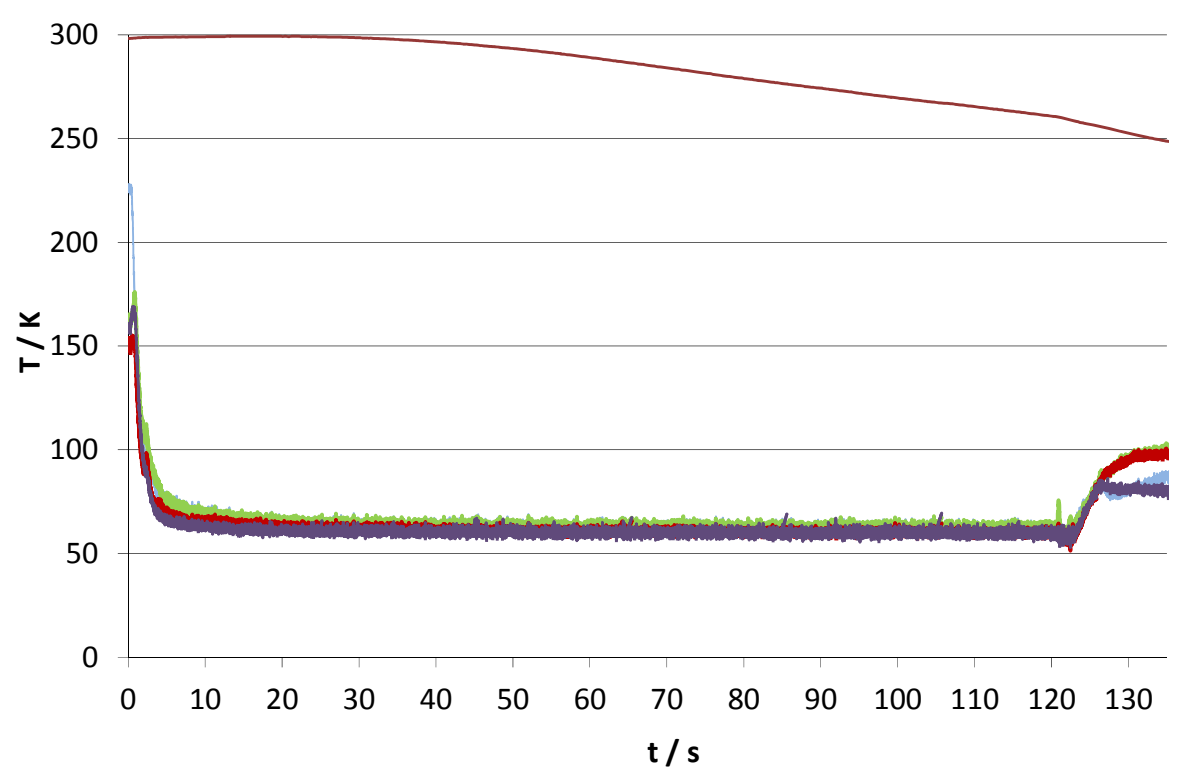

Test Configuration $p_{c}=57$ bar $\tau=15,2 \%$

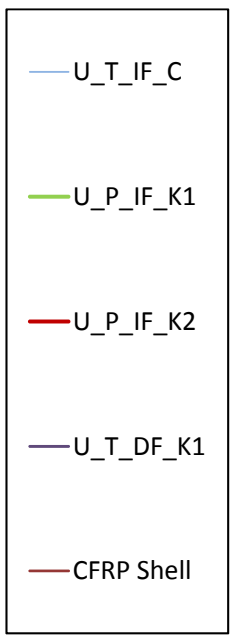

Figure 28. Cryogenic temperature loads ST5 demonstrator, ST5 campaign (P8). Most representative $120 \mathrm{~s}$ long P8-hot-run at a pressure level of $p=55 \mathrm{bar}$.

P6.1 - MT5-A Campaign - 2012 Q1 T06 - HOTRUN - Temperature Courses

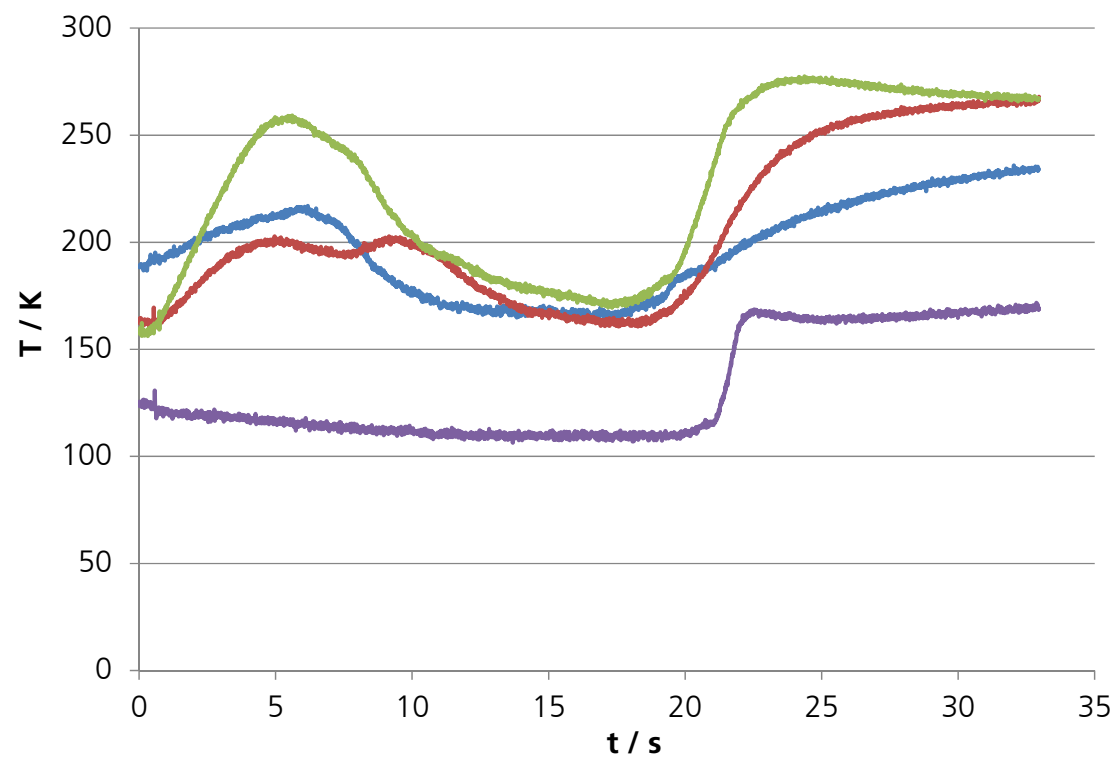

Test configuration $\mathrm{p}_{\mathrm{c}}=\mathbf{6 0} \mathrm{bar}$ $\tau \rightarrow \mathbf{9 , 8 7} \%$

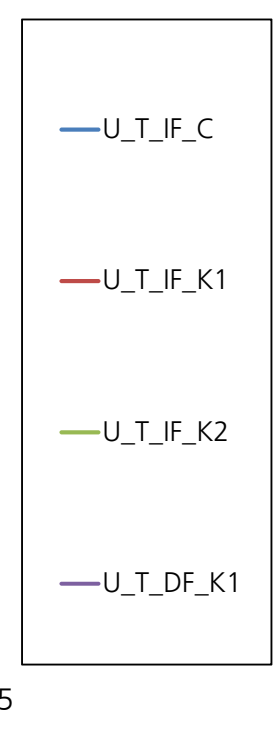

Figure 29. Cryogenic temperature loads ST5 demonstrator, MT5-A campaign (P6.1). $20 \mathrm{~s}$ long P6.1-hot-run at a pressure level of $p=60$ bar after 15 seconds of pre-cooling. 
During the test campaign and after each single test the torque moments of the bolt interface nuts have been checked due to the indication of retention force loss. The nominal torque moment of $40 \mathrm{Nm}$ never decreased all over the campaign duration.

Finally the demonstration test campaigns (figure 30) proved all development goals in form of safe test operation. Apart from the fact, that the operation loads could be managed excellently, it could be demonstrated, that the drastic design simplification actually indicates operational safety. Furthermore multiple tests without any damage occurrence, in particular at the continuous inner CMC liner, could be performed in the meantime. Even under efficient cooling conditions (efficiently low coolant mass flow ratios), as given in figure 30 (right), the functionality of the thrust chamber system could be demonstrated. This is a very motivating conclusion in view to future improvements of high performance CMC rocket thrust chambers.
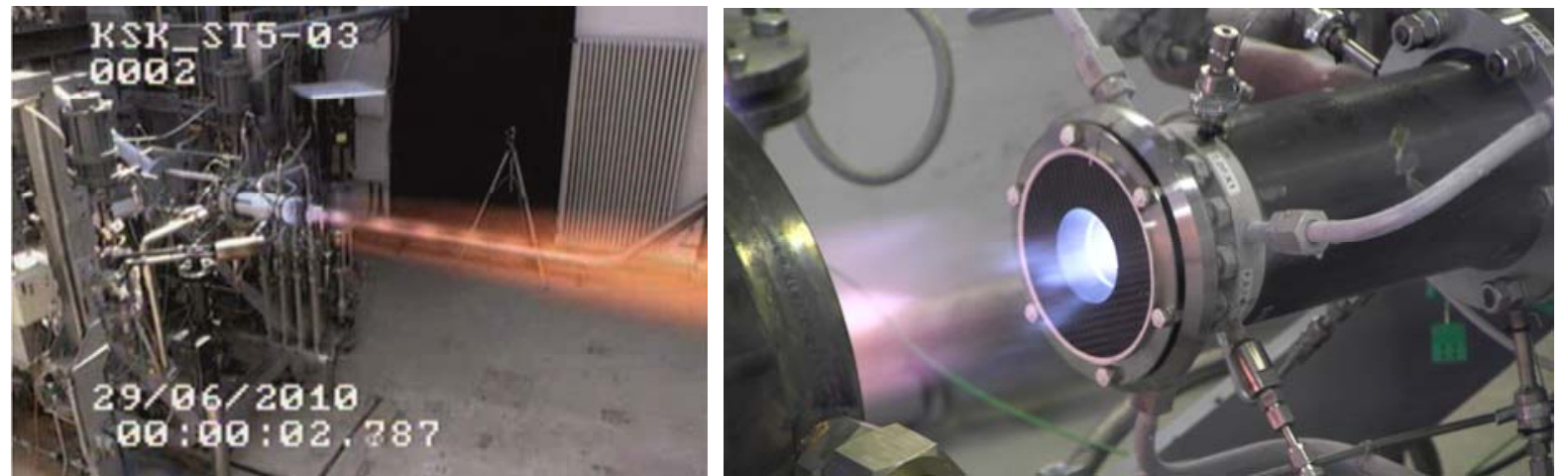

Figure 30. Hot-runs of the ST5 demonstrator. 55 bar hot-run at the P8 test bench (left), 60 bar hot-run, showing $\sim 9.8 \%$ coolant mass flow ratio, at the P6.1 test bench (right).

\section{Conclusion and Outlook}

The integrated design principle of DLR's CMC thrust chamber approach could be demonstrated successfully from multiple points of view.

The general design succeeds currently on the basis of an extensively de-coupled load philosophy. Of high advantage is the absence of interfering load constraints, so that every physical magnitude can be investigated separately. The inner CMC liner works mechanically like a weak spring inside the load carrying housing without being affected by superposition of operational loads.

The combination of different inner liner CMC's is applicable. The different segments are predominantly decoupled and just compressed in axial direction. For tightness reasons and for the prevention of leakage flows respectively, graphite sheets will be inserted between the CMC segments before compression. The CMC segments aren't affected by thermo mechanical mismatches generated by the different material types, because they can slide in radial planes, while being centered by the outer housing. Thermo mechanical mismatches at the inner hot gas surface aren't critical, because in case of transpiration cooling the generated cooling layer shows higher thickness than the tiny geometrical steps.

The application of a load carrying CFRP housing is beneficial due to two major aspects. Firstly the specific light weight supports predominantly the implementation in upper stage engines and secondly the low coefficient of thermal expansion lowers fatigue effects. At the current development status the thermoset matrix promises sufficient tightness against cryogenic hydrogen, considering thicknesses of more than $\mathrm{s}=10 \mathrm{~mm}$.

Three mechanical interface solutions concerning the connection of CFRP housing and metal flanges have been investigated. The clamp mechanism showed at the end of its first investigation loop significant deficit in strength. Hence further improvement is required. The change to a symmetrical clamp design shows potential for applications related to future $\mathrm{CMC}$ interfaces and will be investigated in view to a new CMC nozzle interface. 
The key connector shows in general high potential in the field of fiber reinforced interfaces, which was demonstrated once more in our investigations. But in this application it shows much more need of design space compared to the bolt interface.

The bolt interface seems to be mostly adequate in this case of application. It is robust and shows the simplest manufacturing process. In addition the property of a standard screw connection at metal flange side makes this solution very comfortable. A variety of empirical and analytical effort promised good operation capability concerning the cryogenic high pressure load environment, which could be proved excellently in the test campaigns. The bolt interface nuts were not secured by any safety mechanism. The torque moments at the nuts remained constant throughout the campaign, irrespective of intensive vibration activity during the test runs. This indicates additionally the robustness of this interface solution. Further detailed structural examination of the bolt interface under evaluation of the pre-qualification (chapter V) and the structural behavior in the cryogenic test environment at the test benches will be documented in a future report, considering strain measurements at the CFRP housing conducted in the P8 test campaign.

Currently the entire CMC thrust chamber development at DLR from the very beginning on do not only show a steadily growing potential of transpiration cooled applications, but from all the experience achieved DLR learned furthermore, how to derive applicable CMC solutions in view to regenerative cooled as well as radiation cooled thrust chamber systems. The latter will be additional main pillars in future investigations. But concrete improvements for the transpiration cooling will be continued too, focusing the optimization of the inner liner material design.

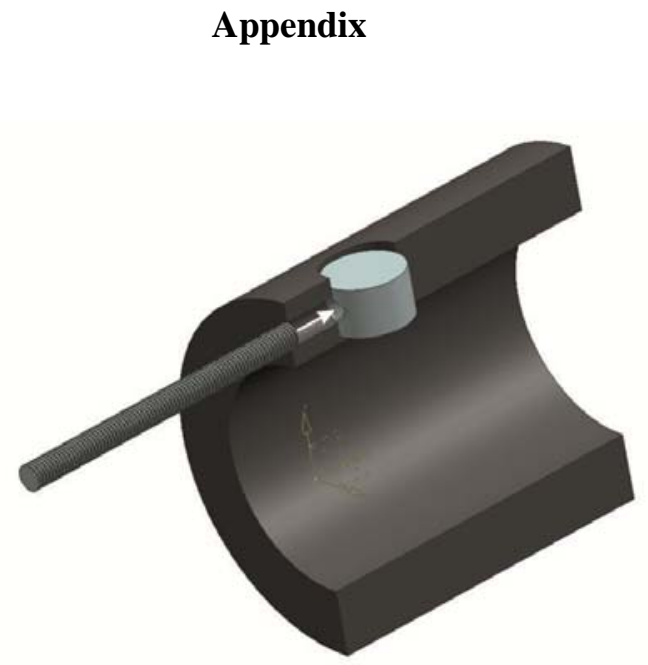

Figure 31. Standard interface solution. Cross-bolt linkage as a standard connection between fiber reinforced plastics and metal structures.

\section{Acknowledgments}

Emphasized thanks shall be given to Walter Pritzkow as well as to the DLR test team at the test benches in Lampoldshausen for their fruitful co-operation. With the aid of WPS material it was possible to perform first screening tests applying oxidic components without long lead time. In addition the colleagues at the test benches always gave support and provided quick solutions in view to unobstructed flow of work during the test campaigns. 


\section{References}

${ }^{1}$ A. Herbertz, M. Ortelt, I. Mueller, H. Hald, Transpiration-Cooled Ceramic Thrust Chamber Applicability for High-Thrust Rocket Engines, June 29 - August 1 2012, 48th AIAA/ASME/SAE/ASEE Joint Propulsion Conference and Exhibit.

${ }^{2}$ Mueller, I., Voggenreiter, H., Untersuchung der Interaktion zwischen einer reaktiven Heissgasströmung und einer transpirativ gekuehlten faserverstaerkten keramischen Raketenbrennkammer, September 27 - $292011,60$. Deutscher Luft- und Raumfahrtkongress 2011, Bremen, Germany.

${ }^{3}$ Greuel, D., Herbertz, A., Haidn, O.J., Ortelt, M., Hald, H., Transpiration Cooling Applied to C/C Liners of Cryogenic Liquid Rocket Engines,, AIAA 2004-3682, July 11 - 14 2004, 40th AIAA/ASME/SAE/ASEE Joint Propulsion Conference and Exhibit.

${ }^{4}$ Hald, H., Ortelt, M., Ghadiani, S., Herbertz, A., Greuel, D., Haidn, O.J.: Application of Fiber Reinforced C/C Ceramic Structures in Liquid Rocket Engines, International Conference (Space 2003), „Space Challenge in 21st Century. 100 Years after the Tsiolkovskiy Idea on Space Missions using Reactive Motors“, Moscow-Kaluga, Russia, 15-19 September 2003.

${ }^{5}$ Heidenreich, B., Herstellung von Faserkeramiken nach dem Fluessigsilicierverfahren (LSI-Technik), in: Keramische Verbundwerkstoffe, Weinheim, Wiley-VCH, pp. 48-75, 2003.

${ }^{6}$ Heidenreich, B., Krenkel, W., Friess, M., Gedon, H., Net Shape manufacturing of Fabric Reinforced Oxide/Oxide Components via Resin Transfer Moulding and Pyrolysis, in: Keramische Verbundwerkstoffe, Weinheim, Wiley-VCH, pp. 48-75, 2003.

${ }^{7}$ Krenkel, W.: Entwicklung eines kostengünstigen Verfahrens zur Herstellung von Bauteilen aus keramischen Verbundwerkstoffen, Institut für Bauweisen und Kostruktionsforschung, Stuttgart, 2000

${ }^{8}$ Lezuo, M., Haidn, O.J., Active Cooling Using Transpiration Devices, 1995, 2nd European Workshop on Thermal Protection Systems, Stuttgart.

${ }^{9}$ Lezuo, M., D., Haidn, O.J., Transpiration Cooling H2/O2 - Combustion Devices, January 26-30 2004, 28th International Cocoa Beach Conference on Advanced Ceramics and Composites, Cocoa Beach, USA

${ }^{10}$ Lux, J., Suslov, D., Haidn, O.J., Experimental Investigation of Porous Injectors for Liquid Propellant Rocket Engines, AIAA 2008-4563, July 21-23 2008, 44th AIAA/ASME/SAE/ASEE Joint Propulsion Conference and Exhibit.

${ }^{11}$ Ortelt, M., Fischer, I., Hald, H., Greuel, D., Suslov, D., Haidn, O.J., Empirical Verification of Effusion Cooled CMC Rocket Thrust Chambers, AIAA 2005-3569, July 10-13 2005, 41st AIAA/ASME/SAE/ASEE Joint Propulsion

${ }^{12}$ Pritzkow, W.E.C., Deuerler, F., Koch, D., Ruedinger, A., Tushtev, K., Versagenseffekte auf Grund von MakroFehlstellen in Oxidkeramischen Verbundwerkstoffe, Bayreuth, Germany, April 1-3 2009, 17. Symposium Verbundwerkstoffe und Werkstoffverbunde.

${ }^{13}$ Ruedinger, A., Glaubitt, W., Oxidkeramische Matrices basierend auf Sol-Gel-Vorstufen fuer die Herstellung oxidkeramischer Faserverbundwerkstoffe, 2005, cfi/Ber. DKG 82 No. 13, 51-54.

${ }^{14}$ Schmidt, S., Beyer, S., Knabe, H., Immich, H., Meistring, R., Gessler, A., Advanced Ceramic Matrix Composite Materials for Current and Future Propulsion Technology Applications, IAC-03-S.3.03, September 29 - October 3rd 2003, 54th Int. Astronautical Congress.

${ }^{15}$ Schmuecker, A., Grafmueller, A., Schneider, H, Mesostructure of WHIPOX all oxide CMC's, Composites: Part A, Elsevier, pp. 613-622, 2003.

${ }^{16}$ Serbest, E.: Untersuchung zur Anwendung der Effusionskühlung bei Raketenbrennkammern, Dissertation, RWTH Aachen, Institut für Luft- und Raumfahrttechnik, Aachen 2002.

${ }^{17}$ N.N.: Forschungstool PANDAS: FE-System zur Simulation von Sonderproblemen der Bodenmechanik (Berechnung volumetrisch stark gekoppelter Festköprer-Fluid-Problemen durch poröse Körper), www.getpandas.com, 2006. 